\title{
Polyhydroxylated Cyclopentane $\beta$-Amino Acids Derived from D-Mannose and D-Galactose: Synthesis and Protocol for Incorporation into Peptides
}

\author{
Fernando Fernández, Alberto G. Fernández, Rosalino Balo, Víctor M. Sánchez-Pedregal, Miriam Royo, \\ Raquel G. Soengas, Ramón J. Estévez, and Juan C. Estévez*
}

Cite This: ACS Omega 2022, 7, 2002-2014

Read Online

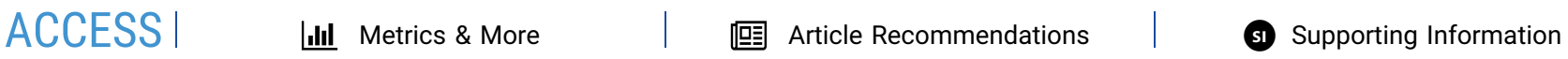

ABSTRACT: A stereoselective synthesis of polyhydroxylated cyclopentane $\beta$ amino acids from hexoses is reported. The reaction sequence comprises, as key steps, ring-closing metathesis of a polysubstituted diene intermediate followed by the stereoselective aza-Michael functionalization of the resulting cyclopent-1-ene1-carboxylic acid ester. Examples of synthesis of polysubstituted 2-aminocyclopentanecarboxylic acid derivatives starting from protected D-mannose and Dgalactose are presented. A general protocol for the incorporation of these highly functionalized alicyclic $\beta$-amino acids into peptides is also reported.

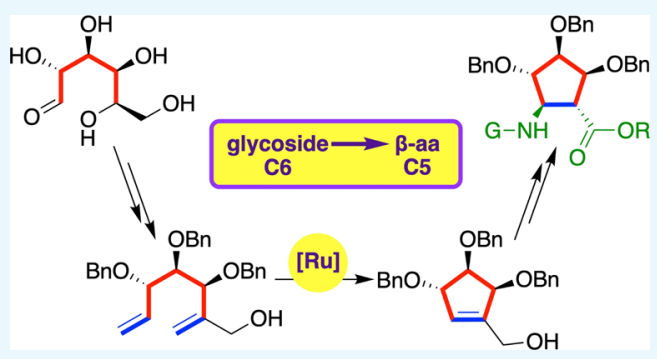

\section{INTRODUCTION}

The enantioselective synthesis of $\beta$-amino acids has received great attention in recent times, ${ }^{1-5}$ mainly because peptidomimetics ${ }^{6}$ based on these amino acids may overcome the pharmacological limitations of natural peptides. ${ }^{7-10}$ They are more resistant than $\alpha$-peptides to protease and peptidase degradation, ${ }^{11-13}$ and their conformational properties and stability facilitate their interaction with receptors and enzymes, which usually results in improved activity and no side effects. ${ }^{14}$ More recently, $\alpha, \beta$-peptides have evidenced promising applications in material sciences, mainly as nanomaterials. ${ }^{15}$

Among the many $\beta$-amino acids that have been studied, cyclopentane-based $\beta$-amino acids are particularly attractive building blocks because their peptides exhibit specific folding properties. For instance, their homo-oligomers show a high propensity to fold in well-defined secondary structures in short peptide sequences, a structural property that often gives them enhanced biostability and activity. ${ }^{16,17}$ Thus, oligomers that contain at least four units of trans-2-aminocyclopentanecarboxylic acids (trans-ACPC) adopt a stable 12-helix with topological dimensions similar to those of the $\alpha$-helix in $\alpha$ peptides, ${ }^{18-20}$ while their cis-homo-oligomers adopt $\beta$-sheet secondary structures. ${ }^{21}$ Homo-oligomers with alternating heterochiral cis-ACPC sequences form a 10/12 helix, while those with alternating heterochiral trans-ACPC tend to attain a polar-strand secondary structure in solution. ${ }^{22}$ In contrast with their homo-oligomers, we demonstrated that short peptides based on alternating trans-ACPC and trans-2-aminocyclohexane adopt a 14-helix fold in aqueous SDS solution but not in organic solvents. ${ }^{23}$ Moreover, cis-ACPC can satisfactorily replace prolines as inducers of $\beta$-turns in $\alpha$-peptides. ${ }^{24,25}$ Controlled self-assembly of helical homo-oligomers of trans-
ACPC in the presence of surfactant gives rise to $3 \mathrm{D}$ nanostructures of different shapes. ${ }^{26,27}$ Accordingly, cyclopentane $\beta$-amino acids proved to be ideal candidates for the stabilization of conformations in peptides.

The development of methodologies for the stereo- and regioselective synthesis of polysubstituted cyclopentane rings continues to be a challenge in synthetic chemistry. ${ }^{28-31} \mathrm{~A}$ specific goal of this significant area of research is to increase the limited number of known polyhydroxylated cyclopentane $\beta$ amino acids ${ }^{3,32,33}$ that would enable access to a larger variety of hydro- or liposoluble cyclopentane-based $\beta$-peptides. This latter goal can be achieved by protection or deprotection of the hydroxyl substituents in polyhydroxylated cyclopentane rings. In addition, it is feasible that these substituents on the cyclopentane rings could result in novel folding properties in $\beta$ peptides, which is a matter of evident interest in materials chemistry. Furthermore, polyhydroxylated cyclopentane $\beta$ amino acids have potential as clinical drugs ${ }^{33,34}$ and biological tools. ${ }^{14,35}$ Also, other molecules containing the polyhydroxylated cyclopentane ring, like some 4-amino-5-(hydroxymethyl)-1,2,3-cyclopentanetriols, have been described as potent glycosidase inhibitors. ${ }^{36-38}$

The first reported polyhydroxylated cyclopentane $\beta$-amino acid was the trans-2-aminocyclopentanecarboxylic acid deriv-

Received: October 1, 2021

Accepted: December 22, 2021

Published: January 4, 2022

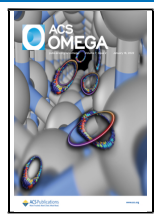


Scheme 1. First Syntheses of Polyhydroxylated Cyclopentane $\beta$-Amino Acids<smiles>O=C1OC2(OCCCC2[N+](=O)[O-])C(Br)C1Br</smiles>

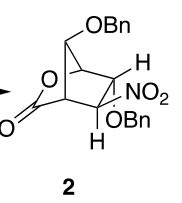<smiles>CC(=O)OC1C(O)C(O)C(O)C1NC(=O)O</smiles><smiles>COC(=O)C1C(NC(=O)OCc2ccccc2)C2OC(C)(C)OC2[C@H]1OC</smiles><smiles>CCOC12OC(=O)C(CCCC1[N+](=O)[O-])C2=O</smiles>

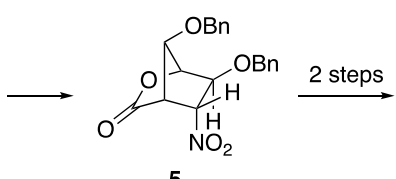<smiles>NC1C(C(=O)O)C(O)[C@@H](O)C1O</smiles>

Scheme 2. Outline of the Synthesis of Functionalized Cyclopentane $\beta$-Amino Acids from Hexoses ${ }^{a}$

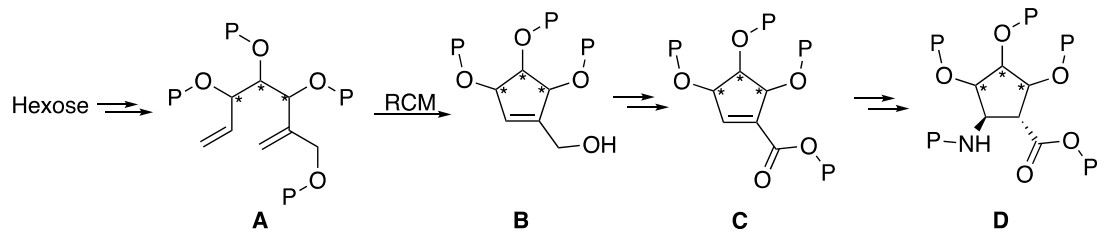

${ }^{a} \mathrm{P}$ : protecting group.

Scheme 3. Synthesis of Polyhydroxylated Cyclopentane $\beta$-Amino acid Derivative $12^{a}$<smiles>[R]OC[C@H](O)[C@H]1O[C@@H](C)[C@H]2OC(C)(C)O[C@H]12</smiles>

$\mathrm{i} \square$ 7a: $\mathrm{R}=\mathrm{H}$

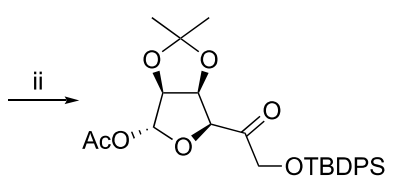

8

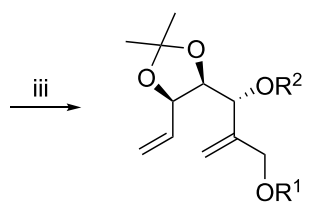

iv 9a: $\mathrm{R}^{1}=$ TBDPS. $\mathrm{R}^{2}=\mathrm{H}$

iv 9b: $R^{1}=$ TBDPS. $R^{2}=\mathrm{Me}$

$\longrightarrow 9 \mathrm{c}: \mathrm{R}^{1}=\mathrm{H} . \mathrm{R}^{2}=\mathrm{Me}$

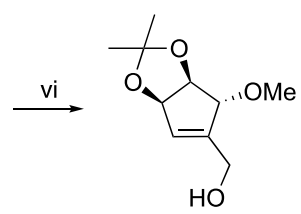

10

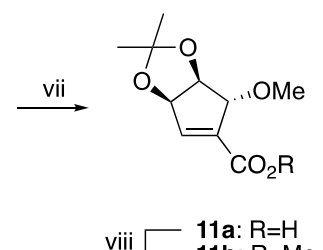

viii $\square$ 11a: $R=H$

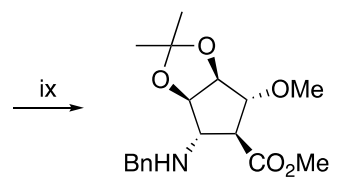

12

${ }^{a}$ Conditions: (i) TBDPSCl, imidazole, $\mathrm{CH}_{2} \mathrm{Cl}_{2}$, rt., 15 min. 98\%. (ii) Dess-Martin, $\mathrm{CH}_{2} \mathrm{Cl}_{2}, \mathrm{rt}$., 2 h, $88 \%$. (iii) $n$ - $\mathrm{BuLi}, \mathrm{Ph}_{3} \mathrm{PCH} \mathrm{Br}_{3}, \mathrm{THF},-78{ }^{\circ} \mathrm{C}$ to rt., $2 \mathrm{~h}, 83 \%$. (iv) $\mathrm{NaH}, \mathrm{MeI}$, THF, $0{ }^{\circ} \mathrm{C}$ to rt., $4 \mathrm{~h}, 95 \%$. (v) TBAF, THF, rt., $2 \mathrm{~h}, 85 \%$. (vi) Grubbs 1 st, $\mathrm{CH}_{2} \mathrm{Cl}_{2}$, rt., $24 \mathrm{~h}, 90 \%$. (vii) a: TEMPO, BAIB, $\mathrm{NBu}_{4} \mathrm{I}, \mathrm{CH}_{2} \mathrm{Cl}_{2} / \mathrm{H}_{2} \mathrm{O}$, rt., 2 h. b: $\mathrm{NaClO}_{2}, \mathrm{NaH}_{2} \mathrm{PO}_{4} \cdot 2 \mathrm{H}_{2} \mathrm{O}$, 2-methyl-2-butene, ${ }^{\mathrm{t}} \mathrm{BuOH} / \mathrm{H}_{2} \mathrm{O}$, rt., 1 h. (viii) $\mathrm{NaHCO}$, $\mathrm{MeI}, \mathrm{DMF}$, rt., 12 h, $85 \%$ (from 10). (ix) $\mathrm{NH}_{2} \mathrm{Bn}, \mathrm{DMF}$, rt., $48 \mathrm{~h}, 91 \%$.

ative 3a, which was obtained in our laboratory by a novel approach involving the key stereocontrolled cyclization of $\mathrm{D}$ glucose nitrosugar derivative $\mathbf{1}$ to bicyclolactone $\mathbf{2}$ (Scheme 1). ${ }^{39,40}$ Amino acid $\mathbf{3 a}$ was converted into its derivative $\mathbf{3 b}$, which is suitably functionalized for incorporation into peptides. ${ }^{40}$ Applications of this approach to L-idose nitrosugar derivative 4 provided the first polyhydroxylated cis-2-aminocyclopentanecarboxylic acid 6 (Scheme 1). ${ }^{41}$ Nevertheless, this strategy turned out unsuitable for preparing peptides based on these $\beta$-amino acids due to the low global yields achieved for 3a ( $12 \%$ yield, seven steps), $3 \mathbf{b}$ ( $8 \%$ yield, 10 steps), and 6 ( $15 \%$ yield, seven steps). Furthermore, the scope of this synthetic strategy is relatively limited because it can provide direct access to only eight polyhydroxylated cyclopentane $\beta$ amino acids, i.e., only those arising from the eight hexoses that meet the stereochemical requirements for the key intramolecular alkylation leading to bicyclic lactones like $\mathbf{2}$ or $\mathbf{5}$ (i.e., D-glucose, D-idose, D-allose, D-talose, L-glucose, L-idose, Lallose and L-talose). ${ }^{42}$

Here, we report a more general and efficient method for the stereocontrolled synthesis of polyhydroxylated cyclopentane $\beta$ amino acids from hexoses. This approach is, in principle, of general application to all hexoses and, in consequence, should give access to a larger variety of relative configurations of these $\beta$-amino acids. Starting from a conveniently protected hexose, the strategy involves the ring-closing metathesis (RCM $)^{43}$ reaction of a richly functionalized diene intermediate $\mathbf{A}$ leading to cyclopentenol B (Scheme 2), which is then transformed into cyclopentene carboxylic acid derivative $\mathbf{C}$, followed by an aza- 
Scheme 4. Synthesis of Polyhydroxylated Cyclopentane $\beta$-Amino Acid Derivative 19a ${ }^{a}$

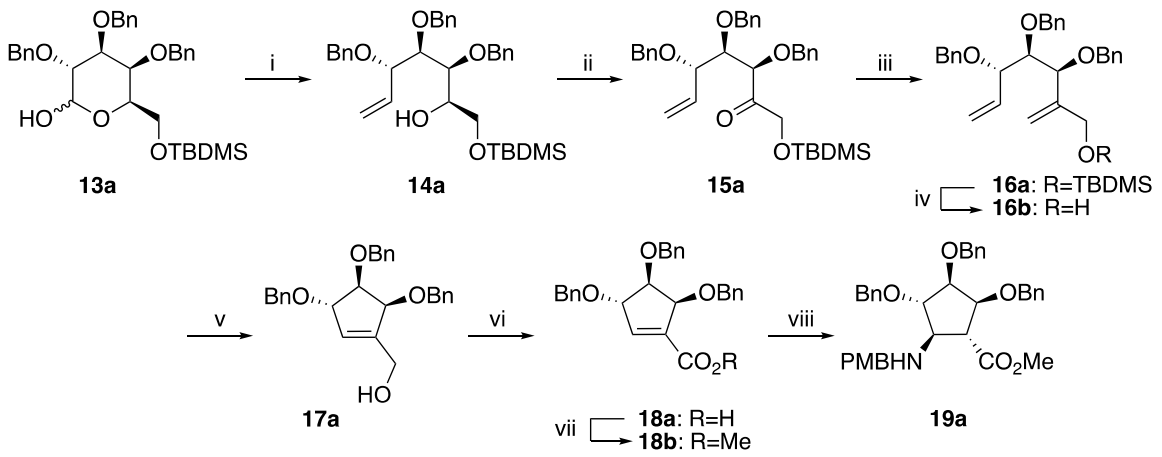

${ }^{a}$ Conditions: (i) $n$-BuLi, $\mathrm{Ph}_{3} \mathrm{PCH} 3 \mathrm{Br}$, THF, $-78^{\circ} \mathrm{C}$ to rt., 12 h, $80 \%$. (ii) Dess-Martin, $\mathrm{CH}_{2} \mathrm{Cl}_{2}$, rt., 2 h, $82 \%$. (iii) $n$-BuLi, $\mathrm{Ph}{ }_{3} \mathrm{PCH}{ }_{3} \mathrm{Br}$, THF, -78

${ }^{\circ} \mathrm{C}$ to rt., $12 \mathrm{~h}, 85 \%$. (iv) TBAF, THF, rt., $1 \mathrm{~h}, 87 \%$, (v) Grubbs 2 nd, toluene, reflux, $24 \mathrm{~h}, 89 \%$. (vi) a: TEMPO, $\mathrm{BAIB} \mathrm{NBu}_{4} \mathrm{I}, \mathrm{CH}_{2} \mathrm{Cl}_{2} / \mathrm{H}_{2} \mathrm{O}, \mathrm{rt}_{\text {., }} 2$ h. b: $\mathrm{NaClO}_{2}, \mathrm{NaH}_{2} \mathrm{PO}_{4} \cdot 2 \mathrm{H}_{2} \mathrm{O}$, 2-methyl-2-butene. (vii) $\mathrm{NaHCO}_{3}, \mathrm{MeI}, \mathrm{DMF}$, rt., 12 h, 97\% (from 17a). (viii) $\mathrm{PMBNH}$, $\mathrm{DMF}$, rt., 24 h, $80 \%$.

Scheme 5. Synthesis of Polyhydroxylated Cyclopentane $\beta$-Amino Acid Derivative $19 b^{a}$
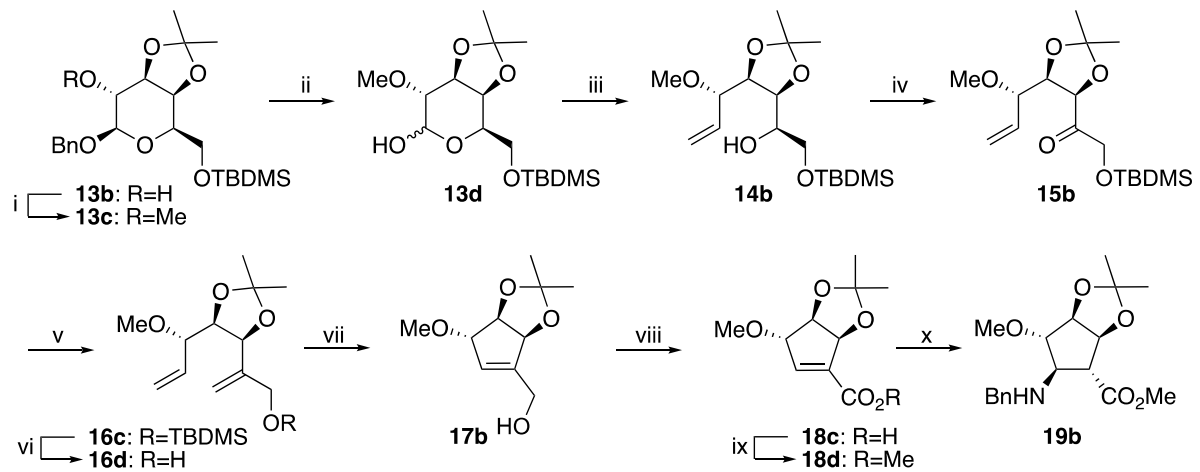

${ }^{a}$ Conditions: (i) $\mathrm{NaH}, \mathrm{MeI}, \mathrm{THF}, 0{ }^{\circ} \mathrm{C}$ to rt., $4 \mathrm{~h}, 93 \%$. (ii) $\mathrm{NH}_{4} \mathrm{HCO}_{2}, \mathrm{Pd} / \mathrm{C}, \mathrm{MeOH}$, rt., $12 \mathrm{~h}, 86 \%$. (iii) $n$ - $\mathrm{BuLi}, \mathrm{Ph} 3 \mathrm{PCH}_{3} \mathrm{Br}$, THF, $-78{ }^{\circ} \mathrm{C}$ to rt., $12 \mathrm{~h}, 80 \%$. (iv) Dess-Martin, $\mathrm{CH}_{2} \mathrm{Cl}_{2}$, rt., $24 \mathrm{~h}, 81 \%$. (v) $n$-BuLi, $\mathrm{Ph}_{3} \mathrm{PCH}_{3} \mathrm{Br}$, THF, $-78{ }^{\circ} \mathrm{C}$ to rt., 2 h, $93 \%$. (vi) TBAF, THF, rt., $1 \mathrm{~h}, 82 \%$. (vii) Grubbs 1st, $\mathrm{CH}_{2} \mathrm{Cl}_{2}$, rt., 24 h, 92\%. (viii) a: TEMPO, BAIB, NBu4I, $\mathrm{CH}_{2} \mathrm{Cl}_{2} / \mathrm{H}_{2} \mathrm{O}$, rt., 2 h. b: $\mathrm{NaClO}_{2}, \mathrm{NaH}_{2} \mathrm{PO}_{4} \cdot 2 \mathrm{H}_{2} \mathrm{O}, 2$-methyl-2-butene. (ix) $\mathrm{NaHCO}_{3}, \mathrm{MeI}, \mathrm{DMF}$, rt., 12 h, 82\% (from 18c). (x) $\mathrm{NH}_{2} \mathrm{Bn}, \mathrm{DMF}$, rt., 24 h, $80 \%$.

Michael amination ${ }^{44}$ of the $\alpha, \beta$-unsaturated carboxylic moiety to give the target highly functionalized $\beta$-amino acid $\mathbf{D}$.

In order to demonstrate the generality of the method, we synthesized protected polyhydroxylated cyclopentane $\beta$-amino acids starting from two hexoses (D-mannose and D-galactose) that cannot give access to them using the previous strategy via nitrosugars. Specifically, starting from D-galactose, we synthesized the derived cyclopentane $\beta$-amino acid with two alternative protecting group schemes suitable for the incorporation into peptides. In one case, we observed an unwanted elimination reaction when trying to couple these $\beta$ amino acids into peptides as already described in a previous work. $^{40}$ Finally, we devised an alternative and more general procedure for the successful incorporation of this type of amino acids into peptides. ${ }^{45}$

\section{RESULTS AND DISCUSSION}

Synthesis of Polyhydroxylated Cyclopentane $\boldsymbol{\beta}$ Amino Acid Derivative 12. In order to demonstrate the feasibility of this strategy with hexoses other than those suitable for the already described intramolecular nitronate cyclization strategy, we synthesized polyhydroxylated cyclopentane $\beta$-amino acid derivative 12 from D-mannose (Scheme 3 ). Selective protection of the primary hydroxyl group of $D-$ mannose derivative $7 a^{46}$ with TBDPS and oxidation of its C5 free hydroxyl group with Dess-Martin reactive gave ketone 8 .
When 8 was submitted to Wittig reaction conditions, a double olefination occurs, one at the ketone group and the other one at the anomeric position, which spontaneously deacetylated in the basic medium of the reaction to give the expected diolefin 9a. Its free hydroxyl group was methylated, and then its silylether was deprotected to give diolefin 9c, which is suitably protected for the RCM reaction.

Cyclopentenol 10 was formed in 90\% yield from 9c under standard RCM reaction conditions using the first-generation Grubbs catalyst. Then, oxidation of the primary hydroxyl group of 10 gave cyclopentenecarboxylic acid 11a. Reaction of 11a with $\mathrm{NaHCO}_{3}$ and $\mathrm{MeI}$ furnished its methyl ester derivative $11 \mathrm{~b}$ in $85 \%$ yield for the last three steps. Finally, treatment of $11 \mathrm{~b}$ with benzylamine resulted in the expected stereoselective aza-Michael addition on the conjugated double bond, which provided compound $\mathbf{1 2}$ in $91 \%$ yield. The total yield for the transformation of $\mathbf{7 a}$ to $\mathbf{1 2}$ was $40 \%$ (nine steps). This yield is much higher than that of the similar $\beta$-amino acid derivative $3 \mathbf{b}$ synthesized from D-glucose by the nitrosugar strategy $(8 \%$ yield, nine steps). ${ }^{40}$

Synthesis of Polyhydroxylated Cyclopentane $\beta$ Amino Acid Derivative 19a. The satisfactory results of our strategy for the transformation of $\mathrm{D}$-mannose into $\beta$-amino acid 12 prompted us to apply it to other hexoses, like the transformation of $\mathrm{D}$-galactose into $\beta$-amino acid 19a (Scheme 4). The key reaction to build the cyclopentane ring of $19 \mathrm{a}$ was 
the RCM reaction of diolefin $16 \mathrm{~b}$, which was prepared from the known D-galactose derivative 13a. ${ }^{47}$ Olefination of the hemiacetal of 13a followed by the oxidation of the hydroxyl group of 14a gave ketone $15 \mathrm{a}$, which was subjected to a second olefination step to give diolefin 16a (Scheme 4). Removal of the silylether group at the $\mathrm{C} 1$ of 16 a by treatment with TBAF gave the desired key diolefin $\mathbf{1 6}$ b. According to our synthetic plan, standard RCM reaction conditions, using the secondgeneration Grubbs catalyst, gave the expected cyclopentenol $17 \mathbf{a}$ in $89 \%$ yield. Oxidation of this compound with TEMPO gave cyclopentenecarboxylic acid 18a through the spontaneous oxidation of the intermediate aldehyde. Reaction of acid 18a with $\mathrm{NaHCO}_{3}$ and $\mathrm{MeI}$ furnished its methyl ester derivative $\mathbf{1 8 b}$ in $97 \%$ yield for the three last steps. The stereoselective aza-Michael addition to the double bond of 18a was performed with $p$-methoxybenzylamine $\left(\mathrm{PMBNH}_{2}\right)$, instead of benzylamine (Scheme 3), to enable the selective deprotection of the amino group of 19a in the presence of the OBn substituents. The total yield of the transformation of 13a into 19a was $34 \%$ for the eight steps.

Synthesis of Polyhydroxylated Cyclopentane $\boldsymbol{\beta}$ Amino Acid Derivative 19b. Next, we devised a different protection pattern for the same hexose that led to the $\beta$-amino acid derivative 19b (Scheme 5), which has its cis hydroxy substituents protected with an isopropylidene substituent. This alternative protecting scheme would open the possibility of selective deprotection of chosen hydroxyl groups. Furthermore, this substitution pattern allows us to compare the efficacy of this synthetic strategy with the one previously reported by us, which had led to the enantiomer (except for the protection of the $\mathrm{N}$ atom, $\mathrm{Bn}$ or $\mathrm{Cbz}$ ) of $19 \mathrm{~b}$ through a modification of the intramolecular nitronate cyclization strategy. ${ }^{48}$

Accordingly, reaction of $\mathrm{D}$-galactose derivative $\mathbf{1 3} \mathbf{b}^{49}$ with methyl iodide gave its $O$-methylated derivative 13 c, which was then converted into the anomeric mixture $13 \mathrm{~d}$ and then into the key diene $16 \mathrm{~d}$, via compounds $14 \mathrm{~b}, 15 \mathrm{~b}$, and 16c (Scheme 5 ), following the protocol leading to its analog $16 \mathrm{~b}$ (Scheme 4). Next, diene $\mathbf{1 6 d}$ was subjected to standard RCM reaction conditions to yield the desired cyclopentenol $\mathbf{1 7 b}$ in $92 \%$ yield. In contrast to cyclization of diene $16 \mathrm{~b}$, this reaction was effective using the first-generation Grubbs catalyst, probably because the steric hindrance is now lower. Compound $17 \mathrm{~b}$ was next converted into cyclopentene carboxylic acid $18 \mathrm{c}$ and then into its ester 18d. The stereoselective aza-Michael addition of $\mathrm{BnNH}_{2}$ led to the cyclopentane $\beta$-amino acid derivative $19 \mathrm{~b}$. This synthesis is noticeably more efficient ( $24 \%$ yield from $\mathbf{1 3 b}$ to $19 \mathrm{~b}, 10$ steps) than the previously described synthesis of the enantiomer (except for the protection of the $\mathrm{N}$ atom, $\mathrm{Bn}$ or $\mathrm{Cbz}$ ) of $19 \mathrm{~b}$ from its nitrosugar precursor 1 ( $8 \%$ yield, nine steps). ${ }^{48}$

It is worth comparing the yields of the two critical steps (ring-closing metathesis and aza-Michael addition) in the above-described synthetic sequences (Schemes 3 to 5). Although all these yields are reasonably high (80-92\%), an attempt to justify the differences can be done. Regarding the RCM reaction, the more reactive second-generation Grubbs catalyst was needed for the transformation $16 \mathbf{b} \rightarrow 17 \mathbf{a}$ (Scheme 4), i.e., with the galactose derivative with its hydroxyls protected with benzyl groups. The reason cannot be the configuration of the starting hexose as the mannose 9c (Scheme 3) and galactose 16d (Scheme 5) derivatives, which have less bulky protecting groups, reacted equally well with the less reactive first-generation Grubbs catalyst. It is unclear if the ultimate reason is the steric hindrance of the relatively bulky benzyl groups of $\mathbf{1 6 b}$ or if it is a consequence of the restrained conformational flexibility of intermediates $9 c$ and $16 d$ due to the protection of their cis-diols as cyclic acetonides; perhaps this might place the double bonds in a position more favorable for the reaction with the less reactive first-generation Grubbs catalyst.

Regarding the aza-Michael step, the yields are similar for the transformations of the galactose derivatives $18 b \rightarrow 19 a(80 \%$; Scheme 4) and $\mathbf{1 8 d} \rightarrow \mathbf{1 9 b}(80 \%$; Scheme 5), while the yield of the mannose derivatives $\mathbf{1 1 b} \rightarrow \mathbf{1 2}$ reaches $91 \%$ (Scheme 3 ). The amine approximates the double bond from the side opposite to the C3 -OR substituent in all cases. That face of the double bond is more hindered in the galactose derivatives (Schemes 4 and 5) than in the mannose derivative (Scheme 3 ), and this could explain the difference in yield.

Synthesis of Tripeptide 21. Next, to demonstrate the usefulness of the orthogonally protected polyhydroxylated cyclopentane $\beta$-amino acids synthesized, we studied the feasibility of their incorporation into short peptide chains by peptide coupling reactions (Schemes 6 and 7). With this

Scheme 6. Incorporation of Polysubstituted Cyclopentane $\beta$-Amino Acid 19a into Peptide $21^{a}$

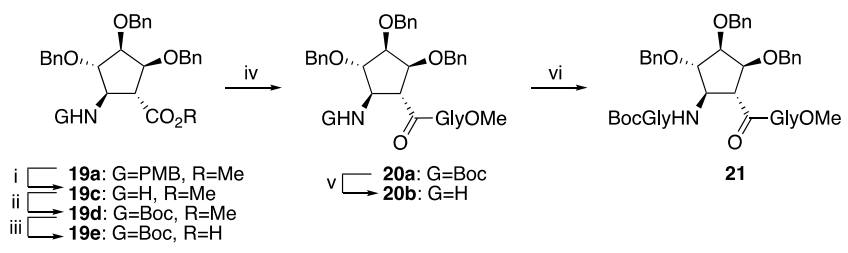

${ }^{a}$ Conditions: (i) CAN, $\mathrm{CH}_{3} \mathrm{CN} / \mathrm{H}_{2} \mathrm{O}, 0{ }^{\circ} \mathrm{C}$ to rt., $6 \mathrm{~h}$, (ii) (Boc) ${ }_{2} \mathrm{O}$, $\mathrm{NaHCO}_{3}$, rt., 18 h, 75\% (from 19a), (iii) $\mathrm{Ba}(\mathrm{OH})_{2} \cdot 8 \mathrm{H}_{2} \mathrm{O}$, THF/ $\mathrm{H}_{2} \mathrm{O}$, rt., 1 h. (iv) $\mathrm{HCl} \cdot \mathrm{HGly}-\mathrm{OMe}$, HATU, DIEA, $\mathrm{CH}_{2} \mathrm{Cl}_{2}$, rt., $14 \mathrm{~h}$ $60 \%$ (from 19d). (v) TFA, THF, rt., 1 h. (vi) Boc-Gly-OH, HATU, DIEA $\mathrm{CH}_{2} \mathrm{Cl}_{2}$, rt., $10 \mathrm{~h}, 55 \%$ (from 20a).

purpose, removal of the PMB-protecting group of 19a with CAN gave the free amine intermediate $19 \mathrm{c}$, which was directly reacted with (Boc) $)_{2} \mathrm{O}$ to furnish the orthogonally protected $\beta$ amino acid ester 19d in $75 \%$ yield in the two steps (Scheme 6). Hydrolysis of the methoxycarbonyl group of compound 19d under mild basic conditions was followed by treatment of the resulting carboxylic acid 19e with HATU as activating reagent and then with glycine hydrochloride. Dipeptide 20a was isolated in $60 \%$ yield (two steps). The $N$-Boc group was easily cleaved with TFA, and the resulting amine $20 \mathrm{~b}$ was reacted with Boc-Gly-OH upon activation with HATU. This furnished tripeptide 21 in $25 \%$ yield from 19a (six steps).

Synthesis of Pentapeptide 24. Incorporation of $19 \mathrm{~b}$ into peptides is more problematic, as hydrolysis of its methyl ester in basic conditions is usually accompanied by the beta elimination of the -OR substituent contiguous to the carboxymethyl alpha position as we previously reported for two analogs of the enantiomer of $19 \mathbf{b} .^{40}$ The solution we devised here involves protecting the carboxylic acid group as trimethylsilylethyl ester (18e; Scheme 7) instead of the methyl ester 18d shown in Scheme 5. This choice of protecting group is made on intermediate $\mathbf{1 8 c}$ prior to the aza-Michael addition. So, starting from carboxylic acid 18c, esterification with trimethylsilylethanol provided the expected cyclopentenecarboxylic acid ester 18e, ${ }^{50}$ which furnished $\beta$-amino acid 
Scheme 7. Protocol for the Incorporation of Polysubstituted Cyclopentane $\beta$-Amino Acid 19b into Peptide $24^{a}$<smiles>CCCCOC(=O)C1=C[C@@H](OC)C2OC(C)(C)OC12</smiles>

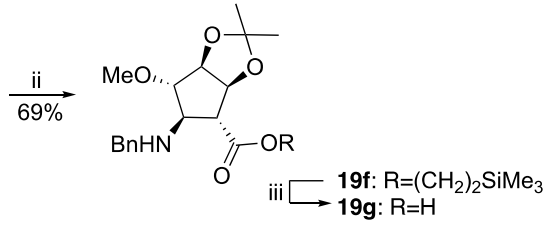

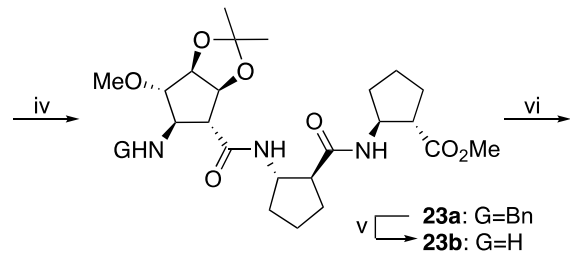<smiles>COC(=O)C1CCCC1NC(=O)C1CCCC1NC(=O)C1CCC(C(=O)NC2CCCC2NC(C)(C)C)C1NC(=O)C1CCCC1</smiles><smiles>O=C(O)OC(=O)C1CCCC1NC(=O)C1CCC[C@H]1NO</smiles>

22a: $\mathrm{G}=\mathrm{H}, \mathrm{R}=\mathrm{Me}$ 22b: $\mathrm{G}=\mathrm{Cbz}, \mathrm{R}=\mathrm{H}$

${ }^{a}$ Conditions: (i) $\mathrm{HO}\left(\mathrm{CH}_{2}\right)_{2} \mathrm{SiMe}_{3}$, DMAP, DCC, $\mathrm{CH}_{2} \mathrm{Cl}_{2}$, rt., 12 h, 77\%. (ii) BnNH , DMF, rt., 60 h, 69\%. (iii) TBAF, THF, rt., 24 h. (iv) 22a, PyBOP, HOBt, DIEA, DMF, 43\% (two steps). (v) $\mathrm{H}_{2}, \mathrm{Pd}(\mathrm{OH})_{2} / \mathrm{C} 20 \%, \mathrm{MeOH}$, overnight. (vi) 22b, PyBOP, HOBt, DIEA, DMF, 59\% (two steps).

derivative $19 \mathrm{f}$ when subjected to the aza-Michael addition using benzylamine as the nucleophile. Hydrolysis of this ester 19f under mild basic conditions with TBAF resulted in carboxylic acid $19 \mathrm{~g}$, which was efficiently transformed into tripeptide 23a by direct coupling with dipeptide 22a. ${ }^{51}$ Removal of the $N$-benzyl-protecting group of 23a, by catalytic hydrogenation, provided its free amino derivative $\mathbf{2 3 b}$, which gave pentapeptide $\mathbf{2 4}$ when reacted with dipeptide $\mathbf{2 2 b}$ under the stated coupling conditions. The overall yield from $18 \mathrm{c}$ was 14\% (six steps).

In conclusion, we present here a promising approach to the stereocontrolled synthesis of highly complex cyclopentane $\beta$ amino acids. This method is more general and efficient than the previously reported alternative from nitrosugars as it could be extended, in principle, to the pool of hexoses. To demonstrate the generality of the method, we applied it to two different hexoses (D-mannose and D-galactose) and with two alternative protecting patterns in the case of $\mathrm{D}$-galactose. This allowed us to synthesize, in the gram scale, three new $\beta$ amino acids (12, 19a, and 19b), which are orthogonally protected for their incorporation into peptides. This method opens up opportunities for a new access to 4-amino-5(hydroxymethyl)-1,2,3-cyclopentanetriols (potent glycosidase inhibitors) by reduction of the methoxycarbonyl group to hydroxymethyl. Furthermore, we have demonstrated how to incorporate these $\beta$-amino acids into peptide chains using classical procedures. In the case of those amino acids that present problems by classical methods, we have also developed an alternative procedure for their incorporation into peptides. The availability of more richly functionalized cyclopentane $\beta$ amino acids, like the ones shown here, would expand the opportunities of designing a larger variety of hydro- or liposoluble $\beta$-peptides. We continue working in the synthesis of monomers and peptides containing hydroxylated groups as well as studying their potential applications in biological chemistry, new materials, and catalysis. As preliminary studies, our immediate plans are directed toward the synthesis of amphiphilic $\beta$-peptides of this nature as potential ice recrystallization inhibitors and gelling agents, which are two issues of great present interest.

\section{EXPERIMENTAL SECTION}

General Information. All nonaqueous reactions were carried out under a positive atmosphere of argon in flame-dried glassware unless otherwise stated. Air- and moisture-sensitive liquid reagents were added by dry syringe or cannula. Anhydrous tetrahydrofuran (THF) was freshly distilled from sodium/benzophenone under argon, and all other solvents and reagents were used as obtained from commercial sources without further purification unless stated. Flash chromatography was performed using 60 Merck 230-400 mesh (flash, 0.04-0.063) silica. Thin-layer chromatography (tlc) was carried out on aluminium-backed sheets coated with 60 GF254 silica. Plates were developed using a spray of $0.2 \% \mathrm{w} / \mathrm{v}$ cerium(IV) sulfate and $5 \%$ ammonium molybdate in $2 \mathrm{M}$ sulfuric acid or in $5 \% \mathrm{w} / \mathrm{v}$ ninhydrin in methanol. ${ }^{1} \mathrm{H}$ and ${ }^{13} \mathrm{C}$ NMR spectra were recorded on Bruker DPX $250(250 \mathrm{MHz}$ for ${ }^{1} \mathrm{H}$ and $62.5 \mathrm{MHz}$ for ${ }^{13} \mathrm{C}$ ) and Varian Mercury 300 (300 $\mathrm{MHz}$ for ${ }^{1} \mathrm{H}$ and $75 \mathrm{MHz}$ for ${ }^{13} \mathrm{C}$ ) spectrometers at room temperature unless otherwise stated. All chemical shifts are quoted on the $\delta$ scale using residual solvent as internal standard; s, d, t, q, m, and br designate singlet, doublet, triplet, quadruplet, multiplet, and broad, respectively. Coupling constants $(J)$ are measured in $\mathrm{Hz}$. Mass spectra were recorded on a Micromass VG-Autospec spectrometer [by chemical ionization $\left(\mathrm{NH}_{3}, \mathrm{CI}\right)$ or electrospray techniques, as stated]. Infrared spectra were recorded on a FT-IR Mattson Cygnus100 spectrometer. Only the characteristic peaks are quoted (in units of $\left.\mathrm{cm}^{-1}\right)$; st, $\mathrm{m}$, and br designate strong, medium, and broad, respectively. All the spectra were measured in $\mathrm{KBr}$ unless stated. Optical rotations were measured on a Jasco DIP370 polarimeter with a path length of $0.5 \mathrm{dm}$ and in a $\mathrm{Na}$ (589 $\mathrm{nm}$ ) lamp. Concentrations are given in $\mathrm{g} / 100 \mathrm{~mL}$. Elemental analyses were carried out on a Carlo Erba EA 1108 analyzer.

Synthesis of Polyhydroxylated Cyclopentane $\boldsymbol{\beta}$ Amino Acid Derivative 12. (3aS,4R,6R,6aS)-6-((R)-2-((tertButyldiphenylsilyl)oxy)-1-hydroxyethyl)-2,2- 
dimethyltetrahydrofuro[3,4-d][1,3]dioxol-4-yl Acetate (7b). A solution of imidazole $(7.04 \mathrm{~g}, 103.33 \mathrm{mmol}), \mathrm{TBDPSCl}$ (12.7 mL, $49.6 \mathrm{mmol}$ ), and compound 7a (10.84 g, 41.33 mmol) in $\mathrm{CH}_{2} \mathrm{Cl}_{2}(83 \mathrm{~mL})$ was stirred at rt. for $15 \mathrm{~min}$ and then washed with water $(100 \mathrm{~mL})$. The organic layer was dried over anhydrous $\mathrm{Na}_{2} \mathrm{SO}_{4}$, filtered, and concentrated to dryness under reduced pressure. Solid residue was purified by flash column chromatography (EtOAc/hexane 1:3) and provided 7 b (20.28 g, $40.51 \mathrm{mmol}, 98 \%$ yield) as a white solid. Mp 88$89{ }^{\circ} \mathrm{C}\left(\mathrm{CH}_{2} \mathrm{Cl}_{2} /\right.$ hexane $) .[\alpha]_{\mathrm{D}}{ }^{22}=+19.1$ (c 1.9, $\left.\mathrm{CHCl}_{3}\right) .{ }^{1} \mathrm{H}$ NMR (250 MHz, $\left.\mathrm{CDCl}_{3}, \mathrm{ppm}\right): \delta 1.06(\mathrm{~s}, 9 \mathrm{H}), 1.35(\mathrm{~s}, 3 \mathrm{H})$, 1.46 (s, 3H), $2.02(\mathrm{~s}, 3 \mathrm{H}), 2.78(\mathrm{br}, 1 \mathrm{H}), 3.85-3.89(\mathrm{~m}, 2 \mathrm{H})$, $4.00-4.10(\mathrm{~m}, 1 \mathrm{H}), 4.19\left(\mathrm{dd}, 1 \mathrm{H}, J_{4,5}=8.2, J_{4,3}=3.3 \mathrm{~Hz}\right), 4.70$ $\left(\mathrm{d}, 1 \mathrm{H}, J_{2,3}=5.8 \mathrm{~Hz}\right), 4.94\left(\mathrm{dd}, 1 \mathrm{H}, J_{3,2}=5.8 \mathrm{~Hz}, J_{3,4}=3.3\right.$ $\mathrm{Hz}), 6.17$ (s, 1H), 7.35-7.47 (m, 6H), 7.63-7.70 (m, 4H). ${ }^{13} \mathrm{C}\left\{{ }^{1} \mathrm{H}\right\} \operatorname{NMR}\left(62.5 \mathrm{MHz}, \mathrm{CDCl}_{3}, \mathrm{ppm}\right): \delta 18.8,20.4,24.4$, 25.6, 26.3, 64.7, 68.8, 79.3, 80.2, 84.3, 100.1, 112.4, 127.3, 129.3, 132.4, 132.6, 135.0, 168.8. IR $\left(\mathrm{NaCl}, \mathrm{cm}^{-1}\right): \nu 3593(\mathrm{br}$, $\mathrm{OH}), 1746$ (st, $\mathrm{C}=\mathrm{O}), 1111$ (st, Si-O-C). MS (CI, $m / z, \%)$ : $501\left(8,[\mathrm{M}+\mathrm{H}]^{+}\right), 484(60), 444$ (100). Anal. calc. for $\mathrm{C}_{27} \mathrm{H}_{36} \mathrm{O}_{7} \mathrm{Si}: \mathrm{C}$, 64.77; H, 7.25. Found: C, 64.67; H, 7.33.

(3aS,4R,6S,6aR)-6-(2-((tert-Butyldiphenylsilyl)oxy)acetyl)2,2-dimethyltetrahydrofuro[3,4-d][1,3]dioxol-4-yl Acetate (8). A solution of compound $7 \mathbf{b}(11.27 \mathrm{~g}, 22.51 \mathrm{mmol})$ in $\mathrm{CH}_{2} \mathrm{Cl}_{2}(106 \mathrm{~mL})$ was stirred with Dess-Martin periodinane (12.41 g, $29.26 \mathrm{mmol}$ ) for $2 \mathrm{~h}$ at room temperature. The mixture was quenched with saturated aq. $\mathrm{Na}_{2} \mathrm{~S}_{2} \mathrm{O}_{3}(50 \mathrm{~mL})$ and extracted with $\mathrm{Et}_{2} \mathrm{O}(50 \mathrm{~mL})$. The organic layer was dried (anhydrous $\mathrm{Na}_{2} \mathrm{SO}_{4}$ ) and concentrated in vacuo. The crude product was purified by flash column chromatography (EtOAc/hexane 1:4) and provided compound 8 (9.88 g, $19.81 \mathrm{mmol}, 88 \%)$ as a white solid. $\mathrm{Mp} 55-56{ }^{\circ} \mathrm{C}\left(\mathrm{CH}_{2} \mathrm{Cl}_{2} /\right.$ hexane). $[\alpha]_{\mathrm{D}}{ }^{21}=-3.5$ (c 1.6, $\mathrm{CHCl}_{3}$ ). ${ }^{1} \mathrm{H} \mathrm{NMR}(250 \mathrm{MHz}$, $\left.\mathrm{CDCl}_{3}, \mathrm{ppm}\right): \delta 1.10(\mathrm{~s}, 9 \mathrm{H}), 1.25(\mathrm{~s}, 3 \mathrm{H}), 1.27(\mathrm{~s}, 3 \mathrm{H}), 2.06$ $(\mathrm{s}, 3 \mathrm{H}), 4.47(\mathrm{~s}, 2 \mathrm{H}), 4.68\left(\mathrm{~d}, 1 \mathrm{H}, J_{2,3}=5.8 \mathrm{~Hz}\right), 4.85(\mathrm{~d}, 1 \mathrm{H}$, $\left.J_{4,3}=4.1 \mathrm{~Hz}\right), 5.20\left(\mathrm{dd}, 1 \mathrm{H}, J_{3,2}=5.8 \mathrm{~Hz}, J_{3,4}=4.1 \mathrm{~Hz}\right), 6.22$ (s, 1H), 7.34-7.44 (m, 6H), 7.65-7.70 (m, 4H). ${ }^{13} \mathrm{C}\left\{{ }^{1} \mathrm{H}\right\}$ NMR (62.5 MHz, $\left.\mathrm{CDCl}_{3}, \mathrm{ppm}\right): \delta 18.9,20.5,24.2,25.3,26.4$, 68.6, 80.0, 83.8, 85.5, 100.0, 113.1, 127.4, 127.5, 129.5, 129.6, 132.1, 132.2, 135.1, 135.2, 168, 202.0. IR $\left(\mathrm{NaCl}, \mathrm{cm}^{-1}\right): \nu$ 1745 (st, C=O), 1113 (st, Si-O-C). MS (CI, $m / z, \%): 499$ (15, $\left.[\mathrm{M}+\mathrm{H}]^{+}\right), 484(27), 440(100)$. Anal. calc. for $\mathrm{C}_{27} \mathrm{H}_{34} \mathrm{O}_{7} \mathrm{Si}$ : C, 65.04; H, 6.87. Found: C, 65.21; H, 7.08.

(R)-2-(((tert-Butyldiphenylsilyl)oxy)methyl)-1-((4S,5R)-2,2dimethyl-5-vinyl-1,3-dioxolan-4-yl)prop-2-en-1-ol (9a). A suspension of $\mathrm{Ph}_{3} \mathrm{PCH}_{3} \mathrm{Br}(1.48 \mathrm{~g}, 4.15 \mathrm{mmol})$ in dry THF $(5 \mathrm{~mL})$ was cooled to $-78{ }^{\circ} \mathrm{C}$ under argon, $n-\mathrm{BuLi}(1.5 \mathrm{~mL}$, $3.82 \mathrm{mmol}, 2.5 \mathrm{M}$ solution in hexane) was added dropwise, and the mixture was stirred at $-78{ }^{\circ} \mathrm{C}$ for $30 \mathrm{~min}$ and at $0{ }^{\circ} \mathrm{C}$ for $30 \mathrm{~min}$. A solution of $8(0.76 \mathrm{~g}, 1.66 \mathrm{mmol})$ in THF (5 $\mathrm{mL}$ ) was added dropwise to the resulting ylide at $-78{ }^{\circ} \mathrm{C}$, and the new reaction mixture was allowed to warm up to room temperature and then heated under reflux for $12 \mathrm{~h}$. The mixture was quenched with saturated aq. $\mathrm{NH}_{4} \mathrm{Cl}(10 \mathrm{~mL})$ and extracted with $\mathrm{Et}_{2} \mathrm{O}(20 \mathrm{~mL})$. The organic layer was dried (anhydrous $\mathrm{Na}_{2} \mathrm{SO}_{4}$ ) and concentrated under reduced pressure. The crude product was purified by flash column chromatography (EtOAc/hexane 1:12) to afford compound 9a $(0.64 \mathrm{~g}, 1.42 \mathrm{mmol}, 85 \%)$ as a yellowish oil. $[\alpha]_{\mathrm{D}}{ }^{20}=-16.1(c$ 1.5, $\mathrm{CHCl}_{3}$ ). ${ }^{1} \mathrm{H}$ NMR (250 MHz, $\left.\mathrm{CDCl}_{3}, \mathrm{ppm}\right): \delta 1.05$ (s, $9 \mathrm{H}), 1.37(\mathrm{~s}, 3 \mathrm{H}), 1.52(\mathrm{~s}, 3 \mathrm{H}), 2.52\left(\mathrm{~d}, 1 \mathrm{H}, J_{\mathrm{OH}, 3}=6.6 \mathrm{~Hz}\right)$, $4.17\left(\mathrm{dd}, 1 \mathrm{H}, J_{3, \mathrm{OH}}=6.6 \mathrm{~Hz}, J_{3,4}=4.4 \mathrm{~Hz}\right), 4.27(\mathrm{br}, 2 \mathrm{H}), 4.31$ $\left(\mathrm{dd}, 1 \mathrm{H}, J_{4,5}=6.9 \mathrm{~Hz}, J_{4,3}=4.4 \mathrm{~Hz}\right), 4.57\left(\mathrm{dd}, 1 \mathrm{H}, J_{5,6}=7.7\right.$
$\left.\mathrm{Hz}, J_{5,4}=6.9 \mathrm{~Hz}\right), 5.21\left(\mathrm{dd}, 1 \mathrm{H}, J_{7 \mathrm{a}, 6}=10.1 \mathrm{~Hz}, J_{7 \mathrm{a}, 7 \mathrm{~b}}=1.4\right.$ $\mathrm{Hz}), 5.24\left(\mathrm{~d}, 1 \mathrm{H}, J_{1 \mathrm{a}, 1 \mathrm{~b}}=1.7 \mathrm{~Hz}\right), 5.28\left(\mathrm{dd}, 1 \mathrm{H}, J_{7 \mathrm{~b}, 6}=17.3 \mathrm{~Hz}\right.$, $\left.J_{7 \mathrm{~b}, 7 \mathrm{a}}=1.4 \mathrm{~Hz}\right), 5.31\left(\mathrm{~d}, 1 \mathrm{H}, J_{1 \mathrm{~b}, 1 \mathrm{a}}=1.7 \mathrm{~Hz}\right), 6.00(\mathrm{ddd}, 1 \mathrm{H}$, $\left.J_{6,7 \mathrm{~b}}=17.3 \mathrm{~Hz}, J_{6,7 \mathrm{a}}=10.1 \mathrm{~Hz}, J_{6,5}=7.7 \mathrm{~Hz}\right), 7.36-7.44(\mathrm{~m}$, 6H), 7.65-7.70 (m, 4H). ${ }^{13} \mathrm{C}\left\{{ }^{1} \mathrm{H}\right\}$ NMR (62.5 $\mathrm{MHz}, \mathrm{CDCl}_{3}$, $\mathrm{ppm}): \delta 19.0,24.7,26.6,27.0,64.7,70.4,78.7,78.9,108.4$, $112.7,118.9,127.5,129.6,133.0,133.9,135.3,146.5$. IR $\left(\mathrm{NaCl}, \mathrm{cm}^{-1}\right): \nu 3514$ (br, OH), 1112 (st, Si-O-C). MS (CI, $m / z, \%): 453\left(5,[\mathrm{M}+\mathrm{H}]^{+}\right), 379(20), 198$ (100). Anal. calc. for $\mathrm{C}_{27} \mathrm{H}_{36} \mathrm{O}_{4} \mathrm{Si}: \mathrm{C}, 71.64 ; \mathrm{H}, 8.02$. Found: C, 71.29; $\mathrm{H}, 8.14$. tert-Butyl((2-((R)-((4R,5R)-2,2-dimethyl-5-vinyl-1,3-dioxolan-4-yl)(methoxy)methyl)allyl)oxy)-diphenylsilane (9b). Sodium hydride $(0.36 \mathrm{~g}, 9.05 \mathrm{mmol}, 60 \%)$ was added in small portions over a $0{ }^{\circ} \mathrm{C}$ cooled solution of $9 \mathrm{a}(2.73 \mathrm{~g}, 6.03 \mathrm{mmol})$ in $24 \mathrm{~mL}$ of dry THF. Once the hydrogen bubbles ceased, methyl iodide $(0.71 \mathrm{~mL}, 11.46 \mathrm{mmol})$ was added, and the reaction was stirred at room temperature for $4 \mathrm{~h}$. Water $(20$ $\mathrm{mL}$ ) was then added, and the mixture was extracted with EtOAc $(20 \mathrm{~mL})$. The organic layer was dried (anhydrous $\mathrm{Na}_{2} \mathrm{SO}_{4}$ ), filtered, and evaporated in vacuo to give compound 9b $(2.67 \mathrm{~g}, 5.73 \mathrm{mmol}, 95 \%)$ as a pure colorless oil. $[\alpha]_{\mathrm{D}}{ }^{20}=$ -18.6 (c 1.1, $\mathrm{CHCl}_{3}$ ). ${ }^{1} \mathrm{H}$ NMR (250 MHz, $\left.\mathrm{CDCl}_{3}, \mathrm{ppm}\right): \delta$ $1.00(\mathrm{~s}, 9 \mathrm{H}), 1.31(\mathrm{~s}, 3 \mathrm{H}), 1.47(\mathrm{~s}, 3 \mathrm{H}), 3.30(\mathrm{~s}, 3 \mathrm{H}), 3.83$ (d, $\left.1 \mathrm{H}, J_{3,4}=4.3 \mathrm{~Hz}\right), 4.28-4.30(\mathrm{~m}, 2 \mathrm{H}), 4.35\left(\mathrm{dd}, 1 \mathrm{H}, J_{4,5}=6.0\right.$ $\left.\mathrm{Hz}, J_{4,3}=4.3 \mathrm{~Hz}\right), 4.63\left(\mathrm{dd}, 1 \mathrm{H}, J_{5,6}=7.7 \mathrm{~Hz}, J_{5,4}=6.0 \mathrm{~Hz}\right)$, $5.18\left(\mathrm{dd}, 1 \mathrm{H}, J_{7 \mathrm{a}, 6}=10.5 \mathrm{~Hz}, J_{7 \mathrm{a}, 7 \mathrm{~b}}=1.6 \mathrm{~Hz}\right), 5.22\left(\mathrm{~d}, 1 \mathrm{H}, J_{1 \mathrm{a}, 1 \mathrm{~b}}\right.$ $=1.4 \mathrm{~Hz}), 5.26\left(\mathrm{dd}, 1 \mathrm{H}, J_{7 \mathrm{~b}, 6}=17.1 \mathrm{~Hz}, J_{7 \mathrm{~b}, 7 \mathrm{a}}=1.6 \mathrm{~Hz}\right), 5.32$ $\left(\mathrm{d}, 1 \mathrm{H}, J_{1 \mathrm{~b}, 1 \mathrm{a}}=1.4 \mathrm{~Hz}\right), 5.97\left(\mathrm{ddd}, 1 \mathrm{H}, J_{6,7 \mathrm{~b}}=17.1 \mathrm{~Hz}, J_{6,7 \mathrm{a}}=\right.$ $\left.10.5 \mathrm{~Hz}, J_{6,5}=7.2 \mathrm{~Hz}\right), 7.37-7.46(\mathrm{~m}, 6 \mathrm{H}), 7.59-7.63(\mathrm{~m}$, $4 \mathrm{H}) .{ }^{13} \mathrm{C}\left\{{ }^{1} \mathrm{H}\right\}$ NMR $\left(62.5 \mathrm{MHz}, \mathrm{CDCl}_{3}, \mathrm{ppm}\right): \delta 19.2,25.0$, 26.5, 27.4, 54.7, 65.1, 70.0, 79.0, 80.4, 108.1, 112.4, 119.7, $127.9,129.3,132.5,133.3,134.7,146.7 . \mathrm{IR}\left(\mathrm{NaCl}, \mathrm{cm}^{-1}\right): \nu$ 1115 (st, Si-O-C). MS (CI, $m / z, \%): 467\left(25,[\mathrm{M}+\mathrm{H}]^{+}\right), 436$ (88), 410 (100). Anal. calc. for $\mathrm{C}_{28} \mathrm{H}_{38} \mathrm{O}_{4} \mathrm{Si}$ : C, 72.06; $\mathrm{H}, 8.21$. Found: C, 71.96; H, 8.15.

2-((R)-((4R,5R)-2,2-Dimethyl-5-vinyl-1,3-dioxolan-4-yl)(methoxy)-methyl)prop-2-en-1-ol (9c). Compound 9b (1.66 $\mathrm{g}, 3.56 \mathrm{mmol})$ was dissolved in THF $(10.7 \mathrm{~mL})$ and stirred with TBAF ( $4.3 \mathrm{~mL}, 4.3 \mathrm{mmol}, 1 \mathrm{M}$ solution in THF) at room temperature for $2 \mathrm{~h}$. The reaction mixture was treated with saturated aq. $\mathrm{NH}_{4} \mathrm{Cl}(25 \mathrm{~mL})$ and extracted with $\mathrm{Et}_{2} \mathrm{O}(25$ $\mathrm{mL}$ ). The organic layer was dried (anhydrous $\mathrm{Na}_{2} \mathrm{SO}_{4}$ ) and concentrated to dryness. The crude product was subjected to flash column chromatography (EtOAc/hexane 1:4) to afford compound 9c $(0.69 \mathrm{~g}, 3.02 \mathrm{mmol}, 85 \%)$ as a yellowish oil. $[\alpha]_{\mathrm{D}}{ }^{19}=-27.3\left(c 1.4, \mathrm{CHCl}_{3}\right) .{ }^{1} \mathrm{H} \mathrm{NMR}\left(250 \mathrm{MHz}, \mathrm{CDCl}_{3}\right.$, ppm): $\delta 1.40(\mathrm{~s}, 3 \mathrm{H}), 1.56(\mathrm{~s}, 3 \mathrm{H}), 2.85(\mathrm{br}, 1 \mathrm{H}), 3.24(\mathrm{~s}$, $3 \mathrm{H}), 3.64\left(\mathrm{~d}, 1 \mathrm{H}, J_{3,4}=4.1 \mathrm{~Hz}\right), 4.08\left(\mathrm{~d}, 1 \mathrm{H}, J_{1 \mathrm{a}, 1 \mathrm{~b}}=13.0 \mathrm{~Hz}\right)$, $4.20\left(\mathrm{~d}, 1 \mathrm{H}, J_{1 \mathrm{~b}, 1 \mathrm{a}}=13.0 \mathrm{~Hz}\right), 4.27\left(\mathrm{dd}, 1 \mathrm{H}, J_{4,5}=6.8 \mathrm{~Hz}, J_{4,3}=\right.$ $4.1 \mathrm{~Hz}), 4.60\left(\mathrm{dd}, 1 \mathrm{H}, J_{5,6}=8.2 \mathrm{~Hz}, J_{5,4}=6.8 \mathrm{~Hz}\right), 5.13(\mathrm{~d}, 1 \mathrm{H}$, $\left.J_{2^{\prime} \mathrm{a}, 2^{\prime} \mathrm{b}}=1.4 \mathrm{~Hz}\right), 5.29\left(\mathrm{dd}, 1 \mathrm{H}, J_{7 \mathrm{~b}, 6}=17.3 \mathrm{~Hz}, J_{7 \mathrm{~b}, 7 \mathrm{a}}=1.7 \mathrm{~Hz}\right)$, $5.34\left(\mathrm{dd}, 1 \mathrm{H}, J_{7 \mathrm{a}, 6}=10.2 \mathrm{~Hz}, J_{7 \mathrm{a}, 7 \mathrm{~b}}=1.7 \mathrm{~Hz}\right), 5.36(\mathrm{~d}, 1 \mathrm{H}$, $\left.J_{2^{\prime} \mathrm{b}, 2^{\prime} \mathrm{a}}=1.4 \mathrm{~Hz},\right), 5.96\left(\mathrm{ddd}, 1 \mathrm{H}, J_{6,7 \mathrm{~b}}=17.3 \mathrm{~Hz}, J_{6,7 \mathrm{a}}=10.2 \mathrm{~Hz}\right.$, $\left.J_{6,5}=8.2 \mathrm{~Hz}\right) \cdot{ }^{13} \mathrm{C}\left\{{ }^{1} \mathrm{H}\right\} \mathrm{NMR}\left(62.5 \mathrm{MHz}, \mathrm{CDCl}_{3}, \mathrm{ppm}\right): \delta$ 24.6, 26.3, 54.8, 60.8, 78.2, 78.7, 81.1, 107.9, 115.1, 117.9, 133.5, 143.9. IR $\left(\mathrm{NaCl}, \mathrm{cm}^{-1}\right): \nu 3462(\mathrm{br}, \mathrm{OH})$. MS (CI, m/ $z, \%): 229\left(13,[\mathrm{M}+\mathrm{H}]^{+}\right), 171$ (12), 166 (100). Anal. calc. for $\mathrm{C}_{12} \mathrm{H}_{20} \mathrm{O}_{4}: \mathrm{C}, 63.14 ; \mathrm{H}, 8.83$. Found: $\mathrm{C}, 62.85 ; \mathrm{H}, 8.67$.

((3aR,4R,6aR)-4-Methoxy-2,2-dimethyl-3a,6a-dihydro-4Hcyclopenta[d][1,3]dioxol-5-yl)methanol (10). Grubbs firstgeneration catalyst $(0.12 \mathrm{~g}, 0.15 \mathrm{mmol})$ was added to a deoxygenated solution of compound $9 \mathrm{c}(0.69 \mathrm{~g}, 3.02 \mathrm{mmol})$ in $\mathrm{Cl}_{2} \mathrm{CH}_{2}(91 \mathrm{~mL})$, and the mixture was refluxed under argon for 
$24 \mathrm{~h}$. Then, the mixture was concentrated to dryness under reduced pressure, and the crude product was purified by flash column chromatography (EtOAc/hexane 1:1) to provide compound 10 (0.55 g, $2.72 \mathrm{mmol}, 90 \%)$ as a yellow oil. $[\alpha]_{\mathrm{D}}^{18}=+31.7\left(c 1.5, \mathrm{CHCl}_{3}\right) .{ }^{1} \mathrm{H} \mathrm{NMR}\left(250 \mathrm{MHz}, \mathrm{CDCl}_{3}\right.$, $\mathrm{ppm}): \delta 1.38(\mathrm{~s}, 3 \mathrm{H}), 1.43(\mathrm{~s}, 3 \mathrm{H}), 2.15(\mathrm{br}, 1 \mathrm{H}), 3.50(\mathrm{~s}$, $3 \mathrm{H}), 4.36\left(\mathrm{~d}, 1 \mathrm{H}, J_{1^{\prime} \mathrm{a}, 1^{\prime} \mathrm{b}}=13.7 \mathrm{~Hz}\right), 4.38\left(\mathrm{~d}, 1 \mathrm{H}, J_{1^{\prime} \mathrm{b}, 1^{\prime} \mathrm{a}}=13.7\right.$ $\mathrm{H}), 4.39(\mathrm{~s}, 1 \mathrm{H}), 4.61\left(\mathrm{~d}, 1 \mathrm{H}, J_{4,3}=5.8 \mathrm{~Hz}\right), 5.20\left(\mathrm{~d}, 1 \mathrm{H}, J_{3,4}=\right.$ $5.8 \mathrm{~Hz}), 5.91(\mathrm{~s}, 1 \mathrm{H}) .{ }^{13} \mathrm{C}\left\{{ }^{1} \mathrm{H}\right\}$ NMR (62.5 MHz, $\mathrm{CDCl}_{3}$, ppm): $\delta 24.8,26.5,56.5,58.7,82.4,82.6,89.0,110.9,127.3$, 146.4. IR $\left(\mathrm{NaCl}, \mathrm{cm}^{-1}\right): \nu 3448$ (br, OH). MS (CI, $\left.m / z, \%\right)$ : $201\left(12,[\mathrm{M}+\mathrm{H}]^{+}\right), 158$ (15), 127 (100). Anal. calc. for $\mathrm{C}_{10} \mathrm{H}_{16} \mathrm{O}_{4}$ : C, 59.98; $\mathrm{H}, 8.05$. Found: C, 59.73; $\mathrm{H}, 8.21$.

Methyl (3aR,4R,6aR)-4-methoxy-2,2-dimethyl-3a,6a-dihydro-4H-cyclopenta[d][1,3]dioxole-5-carboxylate (11b). To a solution of compound $10(0.55 \mathrm{~g}, 2.72 \mathrm{mmol})$ in $\mathrm{CH}_{2} \mathrm{Cl}_{2} / \mathrm{H}_{2} \mathrm{O}$ (19 mL, 3:1), $\mathrm{NBu}_{4} \mathrm{I}(0.05 \mathrm{~g}, 0.14 \mathrm{mmol})$, TEMPO (0.09 g, $0.54 \mathrm{mmol})$, and DAIB $(2.19 \mathrm{~g}, 6.81 \mathrm{mmol})$ were added. The mixture was stirred at room temperature for $2 \mathrm{~h}$, quenched with saturated aq. $\mathrm{Na}_{2} \mathrm{~S}_{2} \mathrm{O}_{3}(35 \mathrm{~mL})$, and extracted with EtOAc $(30 \mathrm{~mL})$. The organic layer was dried (anhydrous $\mathrm{Na}_{2} \mathrm{SO}_{4}$ ) and concentrated in vacuo. The crude product was dissolved in ${ }^{t} \mathrm{BuOH}(13.6 \mathrm{~mL})$ and 2-methyl-2-butene $(2,02$ $\mathrm{mL}, 19.05 \mathrm{mmol})$, and a solution containing $\mathrm{NaClO}_{2}(0.40 \mathrm{~g}$, $3.54 \mathrm{mmol}, 80 \%)$ and $\mathrm{NaH}_{2} \mathrm{PO}_{4} \cdot \mathrm{H}_{2} \mathrm{O}(0.55 \mathrm{~g}, 3.54 \mathrm{mmol})$ in water $(13.6 \mathrm{~mL})$ was added. The mixture was stirred at room temperature for $1 \mathrm{~h}$, quenched with $10 \%$ aq. $\mathrm{HCl}(20 \mathrm{~mL})$, and extracted with EtOAc $(20 \mathrm{~mL})$. The organic layer was dried (anhydrous $\mathrm{Na}_{2} \mathrm{SO}_{4}$ ) and concentrated in vacuo. To a solution of the resulting carboxylic acid in dry DMF $(13.6 \mathrm{~mL})$, $\mathrm{NaHCO}_{3}(0.43 \mathrm{~g}, 5.17 \mathrm{mmol})$ and $\mathrm{MeI}(0.42 \mathrm{~mL}, 6.81 \mathrm{mmol})$ were added. The mixture was stirred at room temperature for $12 \mathrm{~h}$. The reaction mixture was diluted with $\mathrm{NH}_{4} \mathrm{Cl}(20 \mathrm{~mL})$ and extracted with EtOAc $(20 \mathrm{~mL})$. The organic layer was dried (anhydrous $\mathrm{Na}_{2} \mathrm{SO}_{4}$ ) and concentrated in vacuo. Flash column chromatography of the crude (EtOAc/hexane 1:4) furnished compound $\mathbf{1 1 b}(0.53 \mathrm{~g}, 2.31 \mathrm{mmol}, 85 \%$ yield from 10) as a colorless oil. $[\alpha]_{\mathrm{D}}{ }^{18}=-16.1$ (c 1.5, $\left.\mathrm{CHCl}_{3}\right) .{ }^{1} \mathrm{H} \mathrm{NMR}$ $\left(250 \mathrm{MHz}, \mathrm{CDCl}_{3}, \mathrm{ppm}\right): \delta 1.36(\mathrm{~s}, 3 \mathrm{H}), 1.38(\mathrm{~s}, 3 \mathrm{H}), 3.51(\mathrm{~s}$, $3 \mathrm{H}), 3.80(\mathrm{~s}, 3 \mathrm{H}), 4.54\left(\mathrm{~d}, 1 \mathrm{H}, J_{5,4}=1.6 \mathrm{~Hz}\right), 4.61\left(\mathrm{~d}, 1 \mathrm{H}, J_{3,4}\right.$ $=5.2 \mathrm{~Hz}), 5.43\left(\mathrm{dd}, 1 \mathrm{H}, J_{4,3}=5.2 \mathrm{~Hz}, J_{4}=1.6 \mathrm{~Hz}\right), 6.80(\mathrm{~s}$, 1H). ${ }^{13} \mathrm{C}\left\{{ }^{1} \mathrm{H}\right\}$ NMR $\left(62.5 \mathrm{MHz}, \mathrm{CDCl}_{3}, \mathrm{ppm}\right): \delta$ 25.1, 26.7, 51.2, 57.4, 81.9, 82.8, 86.9, 111.2, 136.4, 144.0, 163.0. IR $\left(\mathrm{NaCl}, \mathrm{cm}^{-1}\right): \nu 1726$ (st, C=O). MS (CI, $\left.m / z, \%\right): 229(7$, $\left.[\mathrm{M}+\mathrm{H}]^{+}\right), 197(8), 186(100)$. Anal. calc. for $\mathrm{C}_{11} \mathrm{H}_{16} \mathrm{O}_{5}: \mathrm{C}$, 57.89; H, 7.07. Found: C, 57.73; H, 7.01.

Methyl (3aR,4S,5S,6R,6aS)-4-(benzylamino)-6-methoxy2,2-dimethyltetrahydro-4H-cyclopenta[d][1,3]dioxole-5-carboxylate (12). Benzylamine $(0.72 \mathrm{~mL}, 6.60 \mathrm{mmol})$ was added over a solution of compound $11 \mathbf{b}(1.26 \mathrm{~g}, 5.50 \mathrm{mmol})$ in dry DMF $(16.5 \mathrm{~mL})$, and the resulting solution was stirred at room temperature for $48 \mathrm{~h}$. The reaction mixture was then poured into a saturated aqueous solution of $\mathrm{NH}_{4} \mathrm{Cl}(20 \mathrm{~mL})$ and extracted with EtOAc $(20 \mathrm{~mL})$. The organic layer was dried (anhydrous $\mathrm{Na}_{2} \mathrm{SO}_{4}$ ), filtered, and evaporated in vacuo. The resulting residue was submitted to flash column chromatography (EtOAc/hexane 1:3), to give compound 12 (1.67 g, 4.98 mmol, $91 \%$ yield $)$ as a pale yellow oil. $[\alpha]_{\mathrm{D}}{ }^{17}=-56.8($ c 1.8 , $\left.\mathrm{CHCl}_{3}\right) .{ }^{1} \mathrm{H} \mathrm{NMR}\left(250 \mathrm{MHz}, \mathrm{CDCl}_{3}, \mathrm{ppm}\right): \delta 1.31(\mathrm{~s}, 3 \mathrm{H})$, $1.47(\mathrm{~s}, 3 \mathrm{H}), 1.92(\mathrm{br}, 1 \mathrm{H}), 2.86\left(\mathrm{dd}, 1 \mathrm{H}, J_{1,2}=8.8 \mathrm{~Hz}, J_{1,5}=\right.$ $7.9 \mathrm{~Hz}), 3.41(\mathrm{~s}, 3 \mathrm{H}), 3.43\left(\mathrm{dd}, 1 \mathrm{H}, J_{2,1}=8.8 \mathrm{~Hz}, J_{2,3}=2.7\right.$ $\mathrm{Hz}), 3.72(\mathrm{~s}, 3 \mathrm{H}), 3.77\left(\mathrm{~d}, 1 \mathrm{H}, J_{\mathrm{H}, \mathrm{H}^{\prime}}=13.0 \mathrm{~Hz}\right), 3.91(\mathrm{~d}, 1 \mathrm{H}$, $\left.J_{\mathrm{H}, \mathrm{H}^{\prime}}=13.0 \mathrm{~Hz}\right), 4.06\left(\mathrm{dd}, 1 \mathrm{H}, J_{5,1}=7.9 \mathrm{~Hz}, J_{5,4}=2.5 \mathrm{~Hz}\right)$,
4.47-4.55 (m, 2H), 7.24-7.35 (m, 5H). ${ }^{13} \mathrm{C}\left\{{ }^{1} \mathrm{H}\right\}$ NMR (62.5 $\left.\mathrm{MHz}_{\mathrm{CDCl}}, \mathrm{ppm}\right): \delta 24.5,26.3,51.2,51.6,54.3,57.1,64.3$, 83.2, 84.4, 86.1, 112.4, 126.5, 127.7, 127.9, 139.5, 171.8. IR $\left(\mathrm{NaCl}, \mathrm{cm}^{-1}\right): \nu 3325$ (br, NH), 1737 (st, C=O). MS (CI, m/ $z, \%): 336\left(100,[\mathrm{M}+\mathrm{H}]^{+}\right), 304$ (22), 262 (27). Anal. calc. for $\mathrm{C}_{18} \mathrm{H}_{25} \mathrm{NO}_{5}$ : C, 64.46; H, 7.51; N, 4.18. Found: C, 64.17; H, 7.53; N, 4.04 .

Synthesis of Polyhydroxylated Cyclopentane $\boldsymbol{\beta}$ Amino Acid Derivative 19a. (2R,3S,4R,5S)-3,4,5-Tris(benzyloxy)-1-(tert-butyldimethylsilyloxy)hept-6-ene-2-ol (14a). A suspension of $\mathrm{Ph}_{3} \mathrm{PCH}_{3} \mathrm{Br}(7.99 \mathrm{~g}, 22.36 \mathrm{mmol})$ in dry THF $(37.3 \mathrm{~mL})$ was cooled to $-78{ }^{\circ} \mathrm{C}$ under argon, and $n$ BuLi (14 mL, $22.36 \mathrm{mmol}, 1.6 \mathrm{M}$ solution in hexane) was added dropwise. The mixture was stirred at $-78{ }^{\circ} \mathrm{C}$ for $30 \mathrm{~min}$ and at $0{ }^{\circ} \mathrm{C}$ for $30 \mathrm{~min}$. A solution of $13 \mathrm{a}(4.21 \mathrm{~g}, 7.45 \mathrm{mmol})$ in THF $(37.3 \mathrm{~mL})$ was added dropwise to the resulting ylide at $-78{ }^{\circ} \mathrm{C}$, and the new reaction mixture was allowed to warm up to room temperature and then heated under reflux for $12 \mathrm{~h}$. The mixture was quenched with saturated aq. $\mathrm{NH}_{4} \mathrm{Cl}(50 \mathrm{~mL})$ and extracted with $\mathrm{Et}_{2} \mathrm{O}(100 \mathrm{~mL})$. The organic layer was dried (anhydrous $\mathrm{Na}_{2} \mathrm{SO}_{4}$ ) and concentrated in vacuo. The crude product was purified by flash column chromatography (EtOAc/hexane 1:9) to afford compound 14a (3.36 g, 5.96 mmol, $80 \%$ yield) as a yellowish oil. $[\alpha]_{\mathrm{D}}{ }^{20}=-2.1$ (c 1.7, $\mathrm{CHCl}_{3}$ ). ${ }^{1} \mathrm{H}$ NMR $\left(250 \mathrm{MHz}, \mathrm{CDCl}_{3}, \mathrm{ppm}\right): \delta 0.02(\mathrm{~s}, 6 \mathrm{H})$, $0.88(\mathrm{~s}, 9 \mathrm{H}) ; 3.06(\mathrm{~d}, 1 \mathrm{H}, J=4.9 \mathrm{~Hz}), 3.56-3.62(\mathrm{~m}, 2 \mathrm{H})$, $3.79-3.97(\mathrm{~m}, 3 \mathrm{H}), 4.08(\mathrm{dd}, 1 \mathrm{H}, J=7.9 \mathrm{~Hz}, J=4.9 \mathrm{~Hz})$, 4.35 (d, $1 \mathrm{H}, J=11.8 \mathrm{~Hz}) ; 4.43$ (d, $1 \mathrm{H}, J=11.5 \mathrm{~Hz}) ; 4.50$ (d, $1 \mathrm{H}, J=11.5 \mathrm{~Hz}) ; 4.65(\mathrm{~d}, 1 \mathrm{H}, J=11.8 \mathrm{~Hz}), 4.76(\mathrm{br}, 2 \mathrm{H})$, $5.30(\mathrm{dd}, 1 \mathrm{H}, J=17.5,1.6 \mathrm{~Hz}), 5.35(\mathrm{dd}, 1 \mathrm{H}, J=10.5,1.6$ $\mathrm{Hz}$ ), 5.84 (ddd, $1 \mathrm{H}, J=17.6,10.4,7.9 \mathrm{~Hz}$ ), $7.22-7.38$ (m, 15 H). ${ }^{13} \mathrm{C}\left\{{ }^{1} \mathrm{H}\right\}$ NMR $\left(62.5 \mathrm{MHz}, \mathrm{CDCl}_{3}, \mathrm{ppm}\right): \delta-5.5,-5.4$, 18.1, 25.8, 63.3, 70.2, 71.2, 73.2, 75.2, 75.7, 80.9, 82.3, 119.1, $127.4,127.5,127.6,127.8,127.9,128.0,128.1,128.2,128.3$, $135.5,138.1,138.2,138.3$. MS (CI, $m / z, \%): 563(18,[\mathrm{M}+$ $\left.\mathrm{H}]^{+}\right) ; 456$ (23); 91 (100). IR $\left(\mathrm{NaCl}, \mathrm{cm}^{-1}\right): \nu 3492$ (br, OH), 1104 (st, Si-O-C). Anal. Calc. for $\mathrm{C}_{34} \mathrm{H}_{46} \mathrm{O}_{5} \mathrm{Si}$ : C 72.56; $\mathrm{H}$ 8.24. Found: C 72.49; H 8.49.

( $3 R, 4 R, 5 S)-3,4,5$-Tris (benzyloxy) - 1 - ( ( tert butyldimethylsilyl)oxy)hept-6-en-2-one (15a). After compound $14 \mathrm{a}(1.86 \mathrm{~g}, 3.31 \mathrm{mmol})$ was subjected to the procedure for the preparation of $\mathbf{8}$, flash column chromatography of the crude reaction product (EtOAc/hexane 1:15) provided compound $15 \mathrm{a}$ ( $1.52 \mathrm{~g}, 2.72 \mathrm{mmol}, 82 \%$ yield) as a yellowish oil. $[\alpha]_{\mathrm{D}}{ }^{21}=+20.7\left(c 1.9, \mathrm{CHCl}_{3}\right) .{ }^{1} \mathrm{H}$ NMR $(250$ $\left.\mathrm{MHz}, \mathrm{CDCl}_{3}, \mathrm{ppm}\right): \delta-0.03$ (s, $\left.3 \mathrm{H}\right), 0.00$ (s, 3H), 0.87 (s, 9H), 3.87 (dd, $1 \mathrm{H}, J=6.3,4.4 \mathrm{~Hz}), 4.12(\mathrm{dd}, 1 \mathrm{H}, J=7.1,6.3$ $\mathrm{Hz}), 4.22$ (d, $1 \mathrm{H}, J=4.4 \mathrm{~Hz}), 4.38(\mathrm{~d}, 1 \mathrm{H}, J=11.8 \mathrm{sHz}), 4.45$ $(\mathrm{d}, 2 \mathrm{H}, J=10.2 \mathrm{~Hz}), 4.46(\mathrm{br}, 2 \mathrm{H}), 4.60(\mathrm{~d}, 1 \mathrm{H}, J=11.0 \mathrm{~Hz})$, $4.62(\mathrm{~d}, 1 \mathrm{H}, J=11.8 \mathrm{~Hz}), 4.75(\mathrm{~d}, 1 \mathrm{H}, J=11.0 \mathrm{~Hz}), 5.35$ (dd, $1 \mathrm{H}, J=17.3,1.7 \mathrm{~Hz}), 5.40(\mathrm{dd}, 1 \mathrm{H}, J=10.5,1.7 \mathrm{~Hz}), 5.84$ (ddd, $1 \mathrm{H}, J=17.3,10.5,7.1 \mathrm{~Hz}), 7.21-7.38(\mathrm{~m}, 15 \mathrm{H})$. ${ }^{13} \mathrm{C}\left\{{ }^{1} \mathrm{H}\right\} \mathrm{NMR}\left(62.5 \mathrm{MHz}, \mathrm{CDCl}_{3}, \mathrm{ppm}\right): \delta-5.8,-5.6,18.1$, 25.6, 68.9, 70.4, 72.2, 74.7, 80.5, 81.4, 82.6, 119.2, 127.2, 127.3, $127.5,127.6,127.8,127.9,128.0,128.1,134.9,136.9,137.8$, 138.0, 208.0. MS (CI, $m / z, \%): 561\left(85,[\mathrm{M}+\mathrm{H}]^{+}\right) ; 454$ (100), 91 (90). IR ( NaCl, cm $\left.{ }^{-1}\right): \nu 1735$ (st, C=O), 1091 (st, $\mathrm{Si}-\mathrm{O}-\mathrm{C}$ ). Anal. Calc. for $\mathrm{C}_{34} \mathrm{H}_{44} \mathrm{O}_{5} \mathrm{Si}$ : C 72.82; $\mathrm{H}$ 7.91. Found: C 72.66; H 8.03.

(3S,4R,5S)-3,4,5-Tris(benzyloxy)-1-(tert-butyldimethylsilyloxy)-2-methylenhept-6-ene (16a). A suspension of $\mathrm{Ph}_{3} \mathrm{PCH}_{3} \mathrm{Br}(4.01 \mathrm{~g}, 11.23 \mathrm{mmol})$ in dry THF $(11.2 \mathrm{~mL})$ was cooled to $-78{ }^{\circ} \mathrm{C}$ under argon, and $n$-BuLi $(6.8 \mathrm{~mL}, 10.86$ 
mmol, 1.6 M solution in hexane) was added dropwise. The mixture was stirred at $-78{ }^{\circ} \mathrm{C}$ for $30 \mathrm{~min}$ and at $0{ }^{\circ} \mathrm{C}$ for 30 min. A solution of compound $15 \mathrm{a}(2.10 \mathrm{~g}, 3.75 \mathrm{mmol})$ in THF $(11.2 \mathrm{~mL})$ was added dropwise to the ylide at $-78^{\circ} \mathrm{C}$. The reaction mixture was allowed to warm up to room temperature and was stirred for $2 \mathrm{~h}$. The mixture was quenched with saturated aq. $\mathrm{NH}_{4} \mathrm{Cl}(25 \mathrm{~mL})$ and extracted with $\mathrm{Et}_{2} \mathrm{O}$ (50 $\mathrm{mL}$ ). The organic layer was dried with anhydrous $\mathrm{Na}_{2} \mathrm{SO}_{4}$ and concentrated in vacuo. Flash column chromatography of the crude product (EtOAc/hexane 1:19) afforded compound 16a $\left(1.78 \mathrm{~g}, 3.18 \mathrm{mmol}, 85 \%\right.$ yield) as a yellowish oil. $[\alpha]_{\mathrm{D}}{ }^{20}=$ +19.3 (c 1.4, $\left.\mathrm{CHCl}_{3}\right) .{ }^{1} \mathrm{H}$ NMR $\left(250 \mathrm{MHz}, \mathrm{CDCl}_{3}, \mathrm{ppm}\right): \delta$ $0.02(\mathrm{~s}, 3 \mathrm{H}), 0.03(\mathrm{~s}, 3 \mathrm{H}), 0.91(\mathrm{~s}, 9 \mathrm{H}), 3.59$ (dd, $1 \mathrm{H}, J=7.6$, $3.8 \mathrm{~Hz}), 4.10(\mathrm{~d}, 1 \mathrm{H}, J=11.0 \mathrm{~Hz}), 4.12(\mathrm{dd}, 1 \mathrm{H}, J=7.8,7.6$ $\mathrm{Hz}$ ), 4.13 (d, $1 \mathrm{H}, J=12.1 \mathrm{~Hz}), 4.25(\mathrm{br}, 2 \mathrm{H}), 4.32$ (d, $1 \mathrm{H}, J=$ $12.1 \mathrm{~Hz}), 4.45(\mathrm{~d}, 1 \mathrm{H}, J=11.3 \mathrm{~Hz}), 4.57(\mathrm{~d}, 1 \mathrm{H}, J=11.0 \mathrm{~Hz})$, $4.60(\mathrm{~d}, 1 \mathrm{H}, J=3.8 \mathrm{~Hz}), 4.63(\mathrm{~d}, 1 \mathrm{H}, J=11.3 \mathrm{~Hz}), 5.25(\mathrm{dd}$, $1 \mathrm{H}, J=17.6,1.9 \mathrm{~Hz}), 5.28(\mathrm{~d}, 1 \mathrm{H}, J=1.9 \mathrm{~Hz}), 5.32(\mathrm{dd}, 1 \mathrm{H}, J$ $=10.4,1.9 \mathrm{~Hz}), 5.48(\mathrm{~d}, 1 \mathrm{H}, J=1.9 \mathrm{~Hz}), 5.89(\mathrm{ddd}, 1 \mathrm{H}, J=$ 17.6, 10.4, 7.7 Hz), 7.16-7.36 (m, 15H). ${ }^{13} \mathrm{C}\left\{{ }^{1} \mathrm{H}\right\} \operatorname{NMR}(62.5$ $\left.\mathrm{MHz}, \mathrm{CDCl}_{3}, \mathrm{ppm}\right): \delta-5.5,18.2,25.9,63.4,70.0,70.4,74.9$, 79.2, 80.1, 83.7, 113.4, 118.2, 127.3, 127.4, 127.6, 127.9, 128.0, $128.1,136.1,138.2,138.3,138.4,146.4$. MS (CI, $m / z, \%): 559$ $\left(15,[\mathrm{M}+\mathrm{H}]^{+}\right) ; 468(66) ; 91(100)$. IR $\left(\mathrm{NaCl}, \mathrm{cm}^{-1}\right): \nu 1099$ (st, Si-O-C). Anal. calc. for $\mathrm{C}_{35} \mathrm{H}_{46} \mathrm{O}_{4} \mathrm{Si}$ : C 75.23; $\mathrm{H} 8.30$. Found: C 75.37; $\mathrm{H} 8.20$.

(3S,4R,5S)-3,4,5-Tris(benzyloxy)-2-methylenhept-6-ene-1ol (16b). Compound 16a (1.78 g, $3.18 \mathrm{mmol})$ was dissolved in THF (15.9 mL) and stirred with TBAF $(3.8 \mathrm{~mL}, 3.8 \mathrm{mmol}, 1$ $\mathrm{M}$ solution in THF) at room temperature for $1 \mathrm{~h}$. The reaction mixture was treated with saturated aq. $\mathrm{NH}_{4} \mathrm{Cl}(25 \mathrm{~mL})$ and extracted with $\mathrm{Et}_{2} \mathrm{O}(25 \mathrm{~mL})$. The organic layer was dried (anhydrous $\mathrm{Na}_{2} \mathrm{SO}_{4}$ ) and concentrated to dryness. The crude product was subjected to flash column chromatography (EtOAc/hexane 1:4) to afford compound 16b (1.23 g, 2.77 mmol, $87 \%$ yield) as a yellowish oil. $[\alpha]_{\mathrm{D}}{ }^{19}=+26.8(c 1.3$, $\mathrm{CHCl}_{3}$ ). ${ }^{1} \mathrm{H} \mathrm{NMR}\left(250 \mathrm{MHz}, \mathrm{CDCl}_{3}, \mathrm{ppm}\right): \delta 2.85$ (dd, $1 \mathrm{H}, J$ $=7.4,5.2 \mathrm{~Hz}), 2.72(\mathrm{t}, 1 \mathrm{H}, J=5.8 \mathrm{~Hz}), 4.04(\mathrm{dd}, 1 \mathrm{H}, J=7.9$, $7.4 \mathrm{~Hz}), 4.10-4.22(\mathrm{~m}, 3 \mathrm{H}), 4.15(\mathrm{~d}, 1 \mathrm{H}, J=11.5 \mathrm{~Hz}), 4.34$ $(\mathrm{d}, 1 \mathrm{H}, J=12.1 \mathrm{~Hz}), 4.45(\mathrm{~d}, 1 \mathrm{H}, J=11.5 \mathrm{~Hz}), 4.62(\mathrm{~d}, 1 \mathrm{H}, J$ $=12.1 \mathrm{~Hz}), 4.69(\mathrm{~d}, 1 \mathrm{H}, J=11.0 \mathrm{~Hz}), 4.76(\mathrm{~d}, 1 \mathrm{H}, J=11.0$ $\mathrm{Hz}$ ), $5.22(\mathrm{dd}, 1 \mathrm{H}, J=17.3,1.9 \mathrm{~Hz}), 5.29(\mathrm{~d}, 1 \mathrm{H}, J=1.9 \mathrm{~Hz})$, $5.35(\mathrm{dd}, 1 \mathrm{H}, J=10.4,1.9 \mathrm{~Hz}), 5.38(\mathrm{~d}, 1 \mathrm{H}, J=1.9 \mathrm{~Hz}), 5.84$ (ddd, $1 \mathrm{H}, J=17.3,10.4,7.9 \mathrm{~Hz}), 7.20-7.34(\mathrm{~m}, 15 \mathrm{H})$. ${ }^{13} \mathrm{C}\left\{{ }^{1} \mathrm{H}\right\} \operatorname{NMR}\left(62.5 \mathrm{MHz}, \mathrm{CDCl}_{3}, \mathrm{ppm}\right): \delta 62.6,69.7,70.2$, 75.1, 79.9, 80.3, 83.4, 116.4, 118.5, 127.1, 127.3, 127.6, 127.8, 127.9, 128.0, 135.3, 137.7, 137.8, 138.0, 145.4. MS (CI, $m / z$, $\%): 445\left(54,[\mathrm{M}+\mathrm{H}]^{+}\right) ; 231(64) ; 91$ (100). IR $(\mathrm{NaCl}$, $\left.\mathrm{cm}^{-1}\right): \nu 3450$ (br, OH). Anal. calc. for $\mathrm{C}_{29} \mathrm{H}_{32} \mathrm{O}_{4}: \mathrm{C} 78.35 ; \mathrm{H}$ 7.26. Found: C 78.53; H 7.50.

(3S,4R,5S)-1-Hydroxymethyl-3,4,5-tris(benzyloxy)cyclopent-1-ene (17a). Grubbs second-generation catalyst $(0.12 \mathrm{~g}, 0.14 \mathrm{mmol})$ was added to a deoxygenated solution of compound $16 \mathrm{~b}(1.23 \mathrm{~g}, 2.77 \mathrm{mmol})$ in toluene $(83 \mathrm{~mL})$, and the mixture was refluxed under argon for $24 \mathrm{~h}$. The reaction mixture was concentrated to dryness under a vacuum. The crude product was purified by flash column chromatography (EtOAc/hexane 1:2) to provide compound 17a (1.03 g, 2.46 mmol, $89 \%$ yield) as a yellow oil. $[\alpha]_{\mathrm{D}}{ }^{19}=+19.5$ (c 1.7, $\mathrm{CHCl}_{3}$ ). ${ }^{1} \mathrm{H} \mathrm{NMR}\left(250 \mathrm{MHz}, \mathrm{CDCl}_{3}, \mathrm{ppm}\right): \delta 1.70(\mathrm{br}, 1 \mathrm{H})$; $4.03(\mathrm{dd}, 1 \mathrm{H}, J=5.8,4.1 \mathrm{~Hz}), 4.16(\mathrm{~d}, 1 \mathrm{H}, J=14.5 \mathrm{~Hz}), 4.25$ $(\mathrm{d}, 1 \mathrm{H}, J=14.5 \mathrm{~Hz}), 4.53(\mathrm{~d}, 1 \mathrm{H}, J=11.3 \mathrm{~Hz}), 4.63(\mathrm{~d}, 1 \mathrm{H}, J$ $=11.3 \mathrm{~Hz}), 4.64(\mathrm{~d}, 1 \mathrm{H}, J=10.4 \mathrm{~Hz}), 4.67(\mathrm{~d}, 1 \mathrm{H}, J=11.8$
$\mathrm{Hz}), 4.68(\mathrm{~d}, 1 \mathrm{H}, J=10.4 \mathrm{~Hz}), 4.71(\mathrm{~d}, 1 \mathrm{H}, J=5.8 \mathrm{~Hz}), 4.74$ $(\mathrm{d}, 1 \mathrm{H}, J=11.8 \mathrm{~Hz}), 4.77(\mathrm{dd}, 1 \mathrm{H}, J=4.1,1.4 \mathrm{~Hz}), 5.94(\mathrm{~d}$, $1 \mathrm{H}, J=1.4 \mathrm{~Hz}), 7.28-7.40(\mathrm{~m}, 15 \mathrm{H}) .{ }^{13} \mathrm{C}\left\{{ }^{1} \mathrm{H}\right\} \operatorname{NMR}(62.5$ $\left.\mathrm{MHz}, \mathrm{CDCl}_{3}, \mathrm{ppm}\right): \delta 59.7,71.0,71.4,71.9,78.7,83.8,86.0$, $125.1,127.4,127.5,127.6,127.8,128.0,128.1,137.8,137.9$, 138.1, 146.7. MS (CI, $m / z, \%): 417\left(4,[\mathrm{M}+\mathrm{H}]^{+}\right) ; 400(63)$; 91 (100). IR $\left(\mathrm{NaCl}, \mathrm{cm}^{-1}\right): \nu 3301$ (br, NH), 1757 (st, C=O). Anal. calc. for $\mathrm{C}_{27} \mathrm{H}_{28} \mathrm{O}_{4}$ : $\mathrm{C} 77.86 ; \mathrm{H}$ 6.78. Found: $\mathrm{C} 77.70 ; \mathrm{H}$ 6.92 .

Methyl (3S,4R,5S)-3,4,5-tris(benzyloxy)cyclopent-1-ene-1carboxylate (18b). Compound $17 \mathrm{a}(1.03 \mathrm{~g}, 2.46 \mathrm{mmol})$ was subjected to the procedure for the preparation of compound 11b. Compound 18b (1.06 g, $2.39 \mathrm{mmol}, 97 \%$ yield from 17a, two steps) was obtained as a colorless oil after flash column chromatography (EtOAc/hexane 1:6). $[\alpha]_{\mathrm{D}}{ }^{20}=+17.3(c$ 1.2, $\mathrm{CHCl}_{3}$ ). ${ }^{1} \mathrm{H}$ NMR (250 MHz, $\left.\mathrm{CDCl}_{3}, \mathrm{ppm}\right): \delta 3.72(\mathrm{~s}, 3 \mathrm{H})$, $3.98(\mathrm{dd}, 1 \mathrm{H}, J=5.8,4.3 \mathrm{~Hz}), 4.56(\mathrm{~d}, 1 \mathrm{H}, J=11.8 \mathrm{~Hz}), 4.64-$ $4.80(\mathrm{~m}, 6 \mathrm{H}), 4.98(\mathrm{~d}, 1 \mathrm{H}, J=5.8 \mathrm{~Hz}), 7.02(\mathrm{~d}, 1 \mathrm{H}, J=1.4$ $\mathrm{Hz}), 7.28-7.40(\mathrm{~m}, 15 \mathrm{H}) .{ }^{13} \mathrm{C}\left\{{ }^{1} \mathrm{H}\right\} \mathrm{NMR}\left(62.5 \mathrm{MHz}^{\mathrm{CDCl}}{ }_{3}\right.$, $\mathrm{ppm}): \delta 57.5,71.9,72.1,72.3,76.5,84.9,85.3,127.4,127.5$, $127.6,128.0,128.1,128.2,128.3,135.8,137.6,138.1,147.5$, 168.5. MS (CI, $m / z, \%): 445\left(17,[\mathrm{M}+\mathrm{H}]^{+}\right) ; 430(76) ; 91$ (100). IR $\left(\mathrm{NaCl}, \mathrm{cm}^{-1}\right): \nu 1733$ (st, $\left.\mathrm{C}=\mathrm{O}\right)$. Anal. calc. for $\mathrm{C}_{28} \mathrm{H}_{28} \mathrm{O}_{5}$ : C 75.66; $\mathrm{H}$ 6.35. Found: $\mathrm{C} 75.45 ; \mathrm{H} 6.32$.

Methyl (1R,2S,3S,4S,5R)-2,3,4-tris(benzyloxy)-5-((4methoxybenzyl)amino)cyclopentane-1-carboxylate (19a). Compound 18b (1.06 g, $2.39 \mathrm{mmol}$ ) was dissolved in dry DMF $(7.2 \mathrm{~mL})$ and stirred with $\mathrm{PMBNH}_{2}(0.37 \mathrm{~mL}, 2.86$ $\mathrm{mmol}$ ) at room temperature under argon for $24 \mathrm{~h}$. The reaction mixture was diluted with $\mathrm{NH}_{4} \mathrm{Cl}(10 \mathrm{~mL})$ and extracted with EtOAc $(10 \mathrm{~mL})$. The organic layer was dried (anhydrous $\mathrm{Na}_{2} \mathrm{SO}_{4}$ ) and concentrated in vacuo. The crude product was purified by flash column chromatography (EtOAc/hexane 1:4) to afford compound 19a (1.11 g, 1.91 mmol, $80 \%$ yield) as a yellowish oil. $[\alpha]_{\mathrm{D}}{ }^{22}=+27.5($ c 1.8 , $\mathrm{CHCl}_{3}$ ). ${ }^{1} \mathrm{H}$ NMR (250 MHz, $\left.\mathrm{CDCl}_{3}, \mathrm{ppm}\right): \delta 1.87$ (br, $\left.1 \mathrm{H}\right)$, $2.87(\mathrm{dd}, 1 \mathrm{H}, J=5.5,3.3 \mathrm{~Hz}), 3.32(\mathrm{dd}, 1 \mathrm{H}, J=9.0,7.3 \mathrm{~Hz})$, 3.41 (s, 3H), 3.43 (dd, $1 \mathrm{H}, J=9.0,7.1 \mathrm{~Hz}), 3.55$ (dd, $1 \mathrm{H}, J=$ 7.3, $5.5 \mathrm{~Hz}$ ), 3.66 (dd, $1 \mathrm{H}, J=7.1,3.3 \mathrm{~Hz}), 3.72(\mathrm{~s}, 3 \mathrm{H}), 3.76$ $(\mathrm{d}, 1 \mathrm{H}, J=13.0 \mathrm{~Hz}), 3.78(\mathrm{~d}, 1 \mathrm{H}, J=13.0 \mathrm{~Hz}), 4.03-4.26(\mathrm{~m}$, $6 \mathrm{H}), 6.85-6.90(\mathrm{~m}, 2 \mathrm{H}), 7.20-7.36(\mathrm{~m}, 17 \mathrm{H}) .{ }^{13} \mathrm{C}\left\{{ }^{1} \mathrm{H}\right\} \mathrm{NMR}$ $\left(62.5 \mathrm{MHz}, \mathrm{CDCl}_{3}, \mathrm{ppm}\right): \delta 51.6,51.9,53.9,57.5,63.6,72.1$, $72.3,73.3,80.0,80.9,85.9,113.0,126.3,126.5,126.6,126.9$, $127.0,127.1,127.2,130.4,131.8,137.4,137.7,138.3,146.6$, 173.7. MS (CI, $m / z, \%): 582\left(42,[\mathrm{M}+\mathrm{H}]^{+}\right) ; 551(27) ; 91$ (100). IR $\left(\mathrm{NaCl}, \mathrm{cm}^{-1}\right): \nu 3351$ (br, NH), 1751 (st, C=O).

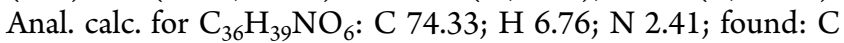
74.12; H 6.52; N 2.21.

Synthesis of Polyhydroxylated Cyclopentane $\boldsymbol{\beta}$ Amino Acid Derivative 19b. (( $3 a S, 4 R, 6 R, 7 R, 7 a S)-6-(B e n z-$ yloxy)-7-methoxy-2,2-dimethyltetrahydro-4H-[1,3]dioxolo[4,5-c]pyran-4-yl)methoxy)(tert-butyl)dimethylsilane (13c). After compound $13 \mathrm{~b}(2.10 \mathrm{~g}, 4.93 \mathrm{mmol})$ was subjected to the procedure for the preparation of $9 b$, compound $13 c$ (2.01 $\mathrm{g}, 4.59 \mathrm{mmol}, 93 \%)$ was obtained as a pure colorless oil. $[\alpha]_{\mathrm{D}}{ }^{20}$ $=-14.5\left(c 1.7, \mathrm{CHCl}_{3}\right) .{ }^{1} \mathrm{H} \mathrm{NMR}\left(250 \mathrm{MHz}, \mathrm{CDCl}_{3}, \mathrm{ppm}\right): \delta$ 0.10 (s, 6H), 0.91 (s, 9H), 1.34 (s, 3H), 1.54 (s, 3H), 3.24 (dd, $1 \mathrm{H}, J=8.0,7.1 \mathrm{~Hz}), 3.60(\mathrm{~s}, 3 \mathrm{H}), 3.74(\mathrm{ddd}, 1 \mathrm{H}, J=7.1,5.5$, $1.9 \mathrm{~Hz}), 3.87(\mathrm{dd}, 1 \mathrm{H}, J=10.1,5.5 \mathrm{~Hz}), 3.93(\mathrm{dd}, 1 \mathrm{H}, J=$ $10.1,7.1 \mathrm{~Hz}$ ), $4.03(\mathrm{dd}, 1 \mathrm{H}, J=7.1,5.4 \mathrm{~Hz}), 4.17(\mathrm{dd}, 1 \mathrm{H}, J=$ 5.4, $1.9 \mathrm{~Hz}), 4.28$ (d, $1 \mathrm{H}, J=8.0 \mathrm{~Hz}), 4.65(\mathrm{~d}, 1 \mathrm{H}, J=11.8$ $\mathrm{Hz}), 4.92(\mathrm{~d}, 1 \mathrm{H}, J=11.8 \mathrm{~Hz}), 7.29-7.39(\mathrm{~m}, 5 \mathrm{H}) .{ }^{13} \mathrm{C}\left\{{ }^{1} \mathrm{H}\right\}$ NMR (62.5 MHz, $\left.\mathrm{CDCl}_{3}, \mathrm{ppm}\right): \delta-5.7,-5.5,18.0,25.6$, 
26.0, 27.9, 60.0, 61.9, 70.0, 73.0, 73.2, 78.8, 82.3, 101.0, 109.4, $127.5,127.7,128.1,137.0$. MS (CI, $m / z, \%): 439$ (11, $[\mathrm{M}+$ $\mathrm{H}^{+}$); 332 (24); 91 (100). IR $\left(\mathrm{NaCl}, \mathrm{cm}^{-1}\right): \nu 1101$ (st, Si-OC). Anal. calc. for $\mathrm{C}_{23} \mathrm{H}_{38} \mathrm{O}_{6} \mathrm{Si}: \mathrm{C}, 62.98 ; \mathrm{H}, 8.73$. Found: $\mathrm{C}$, 62.77; H, 8.55.

(3aS, 4R,6R,7R,7aS)-4-(((tert-Butyldimethylsilyl)oxy)methyl)-7-methoxy-2,2-dimethyltetrahydro-4H-[1,3]dioxolo[4,5-c]pyran-6-ol and (3aS,4R,6S,7R,7aS)-4-(((tertbutyldimethylsilyl)oxy)methyl)-7-methoxy-2,2-dimethyltetrahydro-4H-[1,3]dioxolo[4,5-c]pyran-6-ol (13d). Pd/C (0.64 g, $10 \%)$ and $\mathrm{NH}_{4} \mathrm{HCO}_{2}(4.58 \mathrm{~g}, 72.54 \mathrm{mmol})$ were added sequentially over a deoxygenated solution of $13 \mathrm{c}$ (3.18 g, 7.25 $\mathrm{mmol})$ in $\mathrm{MeOH}(51 \mathrm{~mL})$, and the resulting suspension was refluxed for $12 \mathrm{~h}$. The reaction was then filtered through Celite and washed with $\mathrm{MeOH}$, and the solution was concentrated to dryness under a vacuum. The residue was dissolved in EtOAc $(50 \mathrm{~mL})$ and washed with water $(50 \mathrm{~mL})$; the organic layer was dried (anhydrous $\mathrm{Na}_{2} \mathrm{SO}_{4}$ ) and filtered, and the solvent was removed under a vacuum. The obtained residue was submitted to flash column chromatography (EtOAc/hexane $1: 2)$ to give compounds $13 \mathrm{~d}(2.17 \mathrm{~g}, 6.24 \mathrm{mmol}, 86 \%)$ as a yellow oil. Proportion 2:1 (d.e. 33\%). ${ }^{1} \mathrm{H}$ NMR $(250 \mathrm{MHz}$, $\left.\mathrm{CDCl}_{3}, \mathrm{ppm}\right): \delta 0.08(\mathrm{~s}, 12 \mathrm{H}), 0.89(\mathrm{~s}, 9 \mathrm{H}), 0.90(\mathrm{~s}, 9 \mathrm{H}), 1.35$ $(\mathrm{s}, 6 \mathrm{H}), 1.51(\mathrm{~s}, 3 \mathrm{H}), 1.54(\mathrm{~s}, 3 \mathrm{H}), 3.19-3.24(\mathrm{~m}, 1 \mathrm{H}), 3.36-$ 3.43(m, $2 \mathrm{H}), 3.54(\mathrm{~s}, 3 \mathrm{H}), 3.58(\mathrm{~s}, 3 \mathrm{H}), 3.75-3.87(\mathrm{~m}, 5 \mathrm{H})$, 4.11-4.28 (m, 5H), 4.33-4.39 (m, 1H), 4.65-4.69 (m, 1H), 5.25-5.29 (m, 1H). ${ }^{13} \mathrm{C}\left\{{ }^{1} \mathrm{H}\right\} \mathrm{NMR}\left(62.5 \mathrm{MHz}, \mathrm{CDCl}_{3}, \mathrm{ppm}\right)$ : $\delta-6.0,-5.9,-5.8,17.8,17.9,25.4,25.5,25.6,25.7,27.5$, 27.6, 58.0, 59.3, 61.5, 61.8, 67.2, 72.3, 72.5, 72.6, 74.6, 78.2, 79.1, 82.9, 89.9, 95.7, 108.4, 109.1. MS (CI, $m / z, \%): 349$ (36, $\left.[\mathrm{M}+\mathrm{H}]^{+}\right) ; 332(63) ; 275(100)$. IR $\left(\mathrm{NaCl}, \mathrm{cm}^{-1}\right): \nu 3421$ (br, OH); 1105 (st, Si-O-C). Anal. Calc. for $\mathrm{C}_{16} \mathrm{H}_{32} \mathrm{O}_{6} \mathrm{Si}: \mathrm{C}$, 55.14; H, 9.26. Found: C, 55.27; H, 9.33.

(R)-2-((tert-Butyldimethylsilyl)oxy)-1-((4S,5R)-5-((S)-1-methoxyallyl)-2,2-dimethyl-1,3-dioxolan-4-yl)ethan-1-ol (14b). Starting from the mixture 13d (2.16 g, $6.24 \mathrm{mmol})$ and following the same procedure as per compound 14a, compound 14b was obtained (1.73 g, $4.99 \mathrm{mmol}, 80 \%)$ as a pale yellow oil after flash column chromatography (EtOAc/ hexane 1:7). $[\alpha]_{\mathrm{D}}{ }^{20}=-8.6\left(c\right.$ 1.2, $\left.\mathrm{CHCl}_{3}\right)$. ${ }^{1} \mathrm{H} \operatorname{NMR}(250$ $\left.\mathrm{MHz}, \mathrm{CDCl}_{3}, \mathrm{ppm}\right): \delta 0.07(\mathrm{~s}, 6 \mathrm{H}), 0.89(\mathrm{~s}, 9 \mathrm{H}), 1.38(\mathrm{~s}, 3 \mathrm{H})$, 1.55 (s, 3H), 3.22 (d, $1 \mathrm{H}, J=4.1 \mathrm{~Hz}), 3.34(\mathrm{~s}, 3 \mathrm{H}), 3.60-3.75$ $(\mathrm{m}, 3 \mathrm{H}), 3.93(\mathrm{dd}, 1 \mathrm{H}, J=8.5,3.6 \mathrm{~Hz}), 4.19(\mathrm{~d}, 1 \mathrm{H}, J=10.4$ $\mathrm{Hz}), 4.23$ (d, $1 \mathrm{H}, J=10.4 \mathrm{~Hz}), 5.39(\mathrm{dd}, 1 \mathrm{H}, J=16.7,1.6 \mathrm{~Hz}$ ), $5.41(\mathrm{dd}, 1 \mathrm{H}, J=11.3,1.6 \mathrm{~Hz}), 5.83(\mathrm{ddd}, 1 \mathrm{H}, J=16.7,11.3$, $8.5 \mathrm{~Hz}) .{ }^{13} \mathrm{C}\left\{{ }^{1} \mathrm{H}\right\}$ NMR $\left(62.5 \mathrm{MHz}, \mathrm{CDCl}_{3}, \mathrm{ppm}\right): \delta-5.8$, $-5.7,17.9,24.7,25.5,25.9,55.5,63.5,69.3,75.1,78.8,80.4$, $107.9,119.9,134.3$. MS (CI, $m / z, \%): 347\left(96,[\mathrm{M}+\mathrm{H}]^{+}\right)$; 316 (87); 259 (100). IR $\left(\mathrm{NaCl}, \mathrm{cm}^{-1}\right): \nu 3480$ (br, OH); 1119 (st, Si-O-C). Anal. calc. for $\mathrm{C}_{17} \mathrm{H}_{34} \mathrm{O}_{5} \mathrm{Si}$ : C, 58.92; H, 9.89. Found: C, 59.08; H, 10.18.

2-((tert-Butyldimethylsilyl)oxy)-1-((4R,5R)-5-((S)-1-methoxyallyl)-2,2-dimethyl-1,3-dioxolan-4-yl)ethan-1-one (15b). After compound 14b (1.73 g, $4.99 \mathrm{mmol})$ was subjected to the procedure for the preparation of $15 \mathrm{a}$, flash column chromatography of the crude reaction product (EtOAc/hexane 1:9) provided compound $\mathbf{1 5 b}(1.39 \mathrm{~g}, 4.04 \mathrm{mmol}, 81 \%)$ as a pale yellow oil. $[\alpha]_{\mathrm{D}}{ }^{20}=+91.4\left(c 1.1, \mathrm{CHCl}_{3}\right) .{ }^{1} \mathrm{H}$ NMR $(250$ $\left.\mathrm{MHz}, \mathrm{CDCl}_{3}, \mathrm{ppm}\right): \delta 0.08(\mathrm{~s}, 3 \mathrm{H}), 0.11(\mathrm{~s}, 3 \mathrm{H}), 0.93(\mathrm{~s}, 9 \mathrm{H})$, $1.33(\mathrm{~s}, 3 \mathrm{H}), 1.58(\mathrm{~s}, 3 \mathrm{H}), 3.06(\mathrm{~s}, 3 \mathrm{H}), 3.58(\mathrm{dd}, 1 \mathrm{H}, J=8.5$, $1.6 \mathrm{~Hz}), 4.42(\mathrm{dd}, 1 \mathrm{H}, J=8.2,1.6 \mathrm{~Hz}), 4.45(\mathrm{~d}, 1 \mathrm{H}, J=18.7$ $\mathrm{Hz}), 4.52(\mathrm{~d}, 1 \mathrm{H}, J=8.2 \mathrm{~Hz}), 4.76(\mathrm{~d}, 1 \mathrm{H}, J=18.7 \mathrm{~Hz}), 5.28$ $(\mathrm{dd}, 1 \mathrm{H}, J=17.3,1.6 \mathrm{~Hz}), 5.33(\mathrm{dd}, 1 \mathrm{H}, J=10.4,1.6 \mathrm{~Hz})$,
5.85 (ddd, $1 \mathrm{H}, J=17.3,10.4,8.5 \mathrm{~Hz}) .{ }^{13} \mathrm{C}\left\{{ }^{1} \mathrm{H}\right\} \operatorname{NMR}(62.5$ $\left.\mathrm{MHz} \mathrm{CDCl}_{3}, \mathrm{ppm}\right): \delta-5.7,-5.4,18.2,23.9,25.7,26.0,55.7$, 67.9, 78.9, 79.5, 81.7, 109.9, 119.2, 134.2, 206.8. MS (CI, $m / z$, $\%): 345\left(6,[\mathrm{M}+\mathrm{H}]^{+}\right) ; 314(27) ; 288$ (100). IR ( NaCl, $\left.\mathrm{cm}^{-1}\right): \nu 1750$ (st, $\left.\mathrm{C}=\mathrm{O}\right)$; 1100 (st, Si-O-C). Anal. calc. for $\mathrm{C}_{17} \mathrm{H}_{32} \mathrm{O}_{5} \mathrm{Si}$ : C, 59.27; H, 9.36. Found: C, 59.10; H, 9.47.

tert-Butyl((2-((4S,5R)-5-((S)-1-methoxyallyl)-2,2-dimethyl1,3-dioxolan-4-yl)allyl)oxy)dimethylsilane (16c). When the procedure for the preparation of compound 16a was applied to compound $15 \mathrm{~b}$ (1.39 g, $4.04 \mathrm{mmol})$ and the solid residue from the reaction mixture was subjected to flash column chromatography (EtOAc/hexane 1:19), compound 16c was isolated $(1.29 \mathrm{~g}, 3.77 \mathrm{mmol}, 93 \%)$ as a pale yellow oil. $[\alpha]_{\mathrm{D}}{ }^{20}=$ +32.6 (c 1.6, $\left.\mathrm{CHCl}_{3}\right) .{ }^{1} \mathrm{H} \mathrm{NMR}\left(250 \mathrm{MHz}, \mathrm{CDCl}_{3}, \mathrm{ppm}\right): \delta$ $0.08(\mathrm{~s}, 6 \mathrm{H}) ; 0.92(\mathrm{~s}, 9 \mathrm{H}), 1.38(\mathrm{~s}, 3 \mathrm{H}), 1.54(\mathrm{~s}, 3 \mathrm{H}), 3.23(\mathrm{~s}$, $3 \mathrm{H}), 3.56(\mathrm{dd}, 1 \mathrm{H}, J=7.4,6.0 \mathrm{~Hz}), 4.16(\mathrm{dd}, 1 \mathrm{H}, J=6.6,6.0$ $\mathrm{Hz}), 4.20(\mathrm{~m}, 2 \mathrm{H}), 4.63(\mathrm{~d}, 1 \mathrm{H}, J=6.6 \mathrm{~Hz}), 5.24(\mathrm{dd}, 1 \mathrm{H}, J=$ $17.3,1.9 \mathrm{~Hz}), 5.26(\mathrm{~d}, 1 \mathrm{H}, J=1.6 \mathrm{~Hz}), 5.30(\mathrm{dd}, 1 \mathrm{H}, J=10.7$, $1.9 \mathrm{~Hz}$ ), 5.31 (d, $1 \mathrm{H}, J=1.6 \mathrm{~Hz}), 5.69$ (ddd, $1 \mathrm{H}, J=17.3$, 10.7, 7.4 Hz). ${ }^{13} \mathrm{C}\left\{{ }^{1} \mathrm{H}\right\} \operatorname{NMR}\left(62.5 \mathrm{MHz} \mathrm{CDCl}_{3}, \mathrm{ppm}\right): \delta-$ 5.8, -5.7, 18.0, 24.8, 25.6, 26.1, 55.7, 63.9, 77.9, 80.2, 80.5, $107.9,111.9,118.7,134.6,144.2$. MS (CI, $m / z, \%): 343$ (11, $\left.[\mathrm{M}+\mathrm{H}]^{+}\right) ; 312(49) ; 255(100) . \mathrm{IR}\left(\mathrm{NaCl}, \mathrm{cm}^{-1}\right): \nu 1252$ (st, Si-O-C). Anal. calc. for $\mathrm{C}_{18} \mathrm{H}_{34} \mathrm{O}_{4} \mathrm{Si}: \mathrm{C}, 63.11 ; \mathrm{H}, 10.00$. Found: C, 62.90; H, 10.05.

2-((4S,5R)-5-((S)-1-Methoxyallyl)-2,2-dimethyl-1,3-dioxolan-4-yl)prop-2-en-1-ol (16d). Starting from compound 16c $(1.29 \mathrm{~g}, 3.77 \mathrm{mmol})$ and following the same procedure as per compound $16 \mathrm{~b}$, compound $16 \mathrm{~d}$ was obtained (0.71 g, 3.09 mmol, $82 \%)$ as a pale yellow oil after flash column chromatography (EtOAc/hexane 1:4). $[\alpha]_{\mathrm{D}}{ }^{20}=+66.6(c$ 1.6, $\mathrm{CHCl}_{3}$ ). ${ }^{1} \mathrm{H}$ NMR $\left(250 \mathrm{MHz}, \mathrm{CDCl}_{3}, \mathrm{ppm}\right): \delta 1.39(\mathrm{~s}, 3 \mathrm{H})$, 1.57 (s, 3H), 2.65 (br, 1H), $3.23(\mathrm{~s}, 3 \mathrm{H}), 3.60$ (dd, $1 \mathrm{H}, J=7.9$, $5.2 \mathrm{~Hz}$ ), 4.19 (br, 2H), $4.29(\mathrm{dd}, 1 \mathrm{H}, J=6.9,5.2 \mathrm{~Hz}), 4.76$ (d, $1 \mathrm{H}, J=6.9 \mathrm{~Hz}), 5.21(\mathrm{dd}, 1 \mathrm{H}, J=17.3,1.9 \mathrm{~Hz}), 5.24(\mathrm{~d}, 1 \mathrm{H}, J$ $=1.6 \mathrm{~Hz}), 5.33(\mathrm{dd}, 1 \mathrm{H}, J=10.4,1.9 \mathrm{~Hz}), 5.36\left(\mathrm{~d}, 1 \mathrm{H}, J_{2^{\prime} \mathrm{b}, 2^{\prime} \mathrm{a}}=\right.$ $1.6 \mathrm{~Hz}, \mathrm{H}-2$ 'b), 5.79 (ddd, $1 \mathrm{H}, J_{6,7 \mathrm{~b}}=17.3 \mathrm{~Hz}, J_{6,7 \mathrm{a}}=10.4 \mathrm{~Hz}, J$ $=7.9 \mathrm{~Hz}) .{ }^{13} \mathrm{C}\left\{{ }^{1} \mathrm{H}\right\} \mathrm{NMR}\left(62.5 \mathrm{MHz}, \mathrm{CDCl}_{3}, \mathrm{ppm}\right): \delta 24.3$, 25.8, 55.4, 63.2, 77.7, 79.6, 80.4, 107.8, 112.6, 119.1, 133.9, 144.7. MS (CI, $m / z, \%): 229\left(6,[\mathrm{M}+\mathrm{H}]^{+}\right) ; 186(19) ; 166$ (100). IR $\left(\mathrm{NaCl}, \mathrm{cm}^{-1}\right): \nu 3400$ (br, OH). Anal. calc. for $\mathrm{C}_{12} \mathrm{H}_{20} \mathrm{O}_{4}: \mathrm{C}$, 63.14; $\mathrm{H}, 8.83$. Found: $\mathrm{C}, 63.29 ; \mathrm{H}, 9.05$.

((3aR,4S,6aS)-4-Methoxy-2,2-dimethyl-3a,6a-dihydro-4Hcyclopenta[d][1,3]dioxol-6-yl)methanol (17b). When compound $16 \mathrm{~d}(2.37 \mathrm{~g}, 10.37 \mathrm{mmol})$ was submitted to the same procedure as per compound 10, compound $\mathbf{1 7 b}$ (1.91 g, 9.54 mmol, 92\%) was obtained after flash column chromatography (EtOAc/hexane $1: 1)$ as a yellow oil. $[\alpha]_{\mathrm{D}}{ }^{20}=+31.7(c 1.5$, $\left.\mathrm{CHCl}_{3}\right) .{ }^{1} \mathrm{H} \mathrm{NMR}\left(250 \mathrm{MHz}, \mathrm{CDCl}_{3}, \mathrm{ppm}\right): \delta 1.36(\mathrm{~s}, 3 \mathrm{H})$, $1.41(\mathrm{~s}, 3 \mathrm{H}), 2.16$ (br, $1 \mathrm{H}), 3.43(\mathrm{~s}, 3 \mathrm{H}), 4.25-4.40(\mathrm{~m}, 3 \mathrm{H})$, $4.58(\mathrm{~d}, 1 \mathrm{H}, J=6.0 \mathrm{~Hz}), 5.18(\mathrm{dd}, 1 \mathrm{H}, J=6.0,0.8 \mathrm{~Hz}), 5.78$ $(\mathrm{d}, 1 \mathrm{H}, J=1.4 \mathrm{~Hz}) .{ }^{13} \mathrm{C}\left\{{ }^{1} \mathrm{H}\right\} \mathrm{NMR}\left(62.5 \mathrm{MHz}, \mathrm{CDCl}_{3}, \mathrm{ppm}\right)$ : $\delta$ 24.9, 26.4, 56.0, 58.5, 82.4, 82.6, 88.4, 111.1, 124.3, 148.8 . MS (CI, $m / z, \%): 201\left(20,[\mathrm{M}+\mathrm{H}]^{+}\right) ; 158(18) ; 127$ (100). IR $\left(\mathrm{NaCl}, \mathrm{cm}^{-1}\right): \nu 3448(\mathrm{br}, \mathrm{OH})$. Anal. calc. for $\mathrm{C}_{10} \mathrm{H}_{16} \mathrm{O}_{4}$ : C, 59.98; H, 8.05. Found: C, 59.93; H, 7.85.

Methyl (3aR,4S,6aS)-4-methoxy-2,2-dimethyl-3a,6a-dihydro-4H-cyclopenta[d][1,3]dioxole-6-carboxylate (18d). When compound $\mathbf{1 7 b}(1.91 \mathrm{~g}, 9.54 \mathrm{mmol})$ was subjected to the procedure for the preparation of compound $\mathbf{1 1} \mathbf{b}$, compound 18d (1.79 g, $7.83 \mathrm{mmol}, 82 \%)$ was obtained as a colorless oil after flash column chromatography (EtOAc/ hexane 1:4). $[\alpha]_{\mathrm{D}}{ }^{20}=+26.7\left(c 1.2, \mathrm{CHCl}_{3}\right) .{ }^{1} \mathrm{H}$ NMR $(250$ 
$\left.\mathrm{MHz}, \mathrm{CDCl}_{3}, \mathrm{ppm}\right): \delta 1.39(\mathrm{~s}, 3 \mathrm{H}), 1.43(\mathrm{~s}, 3 \mathrm{H}), 3.46(\mathrm{~s}, 3 \mathrm{H})$, $3.82(\mathrm{~s}, 3 \mathrm{H}), 4.40-4.43(\mathrm{~m}, 1 \mathrm{H}), 4.63(\mathrm{~d}, 1 \mathrm{H}, J=6.0 \mathrm{~Hz})$, $5.43(\mathrm{dd}, 1 \mathrm{H}, J=6.0,1.6 \mathrm{~Hz}), 6.77(\mathrm{~d}, 1 \mathrm{H}, J=1.4 \mathrm{~Hz})$. ${ }^{13} \mathrm{C}\left\{{ }^{1} \mathrm{H}\right\} \mathrm{NMR}\left(62.5 \mathrm{MHz}, \mathrm{CDCl}_{3}, \mathrm{ppm}\right): \delta 24.4,26.2,51.0$, 56.3, 81.6, 82.6, 88.4, 111.5, 138.3, 141.3, 163.1. MS (CI, $m / z$, $\%): 229\left(6,[\mathrm{M}+\mathrm{H}]^{+}\right) ; 197(100) ; 186(9) . \mathrm{IR}\left(\mathrm{NaCl}, \mathrm{cm}^{-1}\right)$ : $\nu 1728$ (st, $\mathrm{C}=\mathrm{O}$ ). Anal. calc. for $\mathrm{C}_{11} \mathrm{H}_{16} \mathrm{O}_{5}$ : C, 57.89; H, 7.07. Found: C, 57.78; H, 7.19.

Methyl (3aS,4R,5R,6S,6aS)-5-(benzylamino)-6-methoxy2,2-dimethyltetrahydro-4H-cyclopenta[d][1,3]dioxole-4-carboxylate (19b). Starting from compound 18d (1.79 g, 7.86 $\mathrm{mmol}$ ) and following the same procedure as for the preparation of compound 12, compound $19 \mathrm{~b}$ (2.10 g, 6.26 mmol, $80 \%$ yield) was obtained as a yellowish oil after flash column chromatography (EtOAc/hexane 1:3). $[\alpha]_{\mathrm{D}}{ }^{20}=+44.6$ (c 1.5, $\left.\mathrm{CHCl}_{3}\right) .{ }^{1} \mathrm{H} \mathrm{NMR}\left(250 \mathrm{MHz}, \mathrm{CDCl}_{3}, \mathrm{ppm}\right): \delta 1.31$ (s, $3 \mathrm{H}), 1.49(\mathrm{~s}, 3 \mathrm{H}), 2.58(\mathrm{~d}, 1 \mathrm{H}, J=3.6 \mathrm{~Hz}), 2.92(\mathrm{dd}, 1 \mathrm{H}, J=$ $9.35 .5 \mathrm{~Hz}), 3.41(\mathrm{~s}, 3 \mathrm{H}), 3.44(\mathrm{ddd}, 1 \mathrm{H}, J=9.3,7.4,3.6 \mathrm{~Hz})$, $3.66(\mathrm{dd}, 1 \mathrm{H}, J=7.4,3.3 \mathrm{~Hz}), 3.71(\mathrm{~s}, 3 \mathrm{H}), 3.78(\mathrm{~d}, 1 \mathrm{H}, J=$ $13.2 \mathrm{~Hz}$ ), 3.84 (d, $1 \mathrm{H}, J=13.2 \mathrm{~Hz}), 4.43(\mathrm{dd}, 1 \mathrm{H}, J=7.1,3.3$ $\mathrm{Hz}), 4.83(\mathrm{dd}, 1 \mathrm{H}, J=7.1,5.5 \mathrm{~Hz}), 7.24-7.34(\mathrm{~m}, 5 \mathrm{H})$. ${ }^{13} \mathrm{C}\left\{{ }^{1} \mathrm{H}\right\}$ NMR $\left(62.5 \mathrm{MHz}, \mathrm{CDCl}_{3}, \mathrm{ppm}\right): \delta 24.0,26.4,50.8$, 51.5, 53.1, 56.9, 64.2, 79.0, 82.4, 89.2, 111.7, 126.4, 127.6, 127.8, 139.5, 172.3. MS (CI, $m / z, \%): 336\left(83,[\mathrm{M}+\mathrm{H}]^{+}\right)$; 304 (12); 262 (100). IR ( NaCl, cm $\left.{ }^{-1}\right): \nu 3339$ (br, NH); 1733 (st, $\mathrm{C}=\mathrm{O}$ ). Anal. calc. for $\mathrm{C}_{18} \mathrm{H}_{25} \mathrm{NO}_{5}$ : C, 64.46; $\mathrm{H}, 7.51 ; \mathrm{N}$, 4.18. Found: C, 64.18; H, 7.39; N, 4.00.

Synthesis of Tripeptide 21. Methyl (1R,2S,3S,4S,5R) -2,3,4-Tris-(benzyloxy)-5-tert-((butoxycarbonyl)amino)cyclopentane-1-carboxylate (19d). CAN (4.19 g, $7.64 \mathrm{mmol}$ ) was added to a solution of compound $19 \mathrm{a}(1.11 \mathrm{~g}, 1.91 \mathrm{mmol})$ in $\mathrm{CH}_{3} \mathrm{CN} / \mathrm{H}_{2} \mathrm{O}(95.5 \mathrm{~mL}, 4: 1)$ at $0{ }^{\circ} \mathrm{C}$. The mixture was allowed to warm up to room temperature and stirred for $6 \mathrm{~h}$. The mixture was quenched with saturated aq. $\mathrm{Na}_{2} \mathrm{~S}_{2} \mathrm{O}_{3}$ (a few drops) and concentrated in vacuo. The crude product was dissolved in dioxane $(38.2 \mathrm{~mL})$ and treated with $(\mathrm{Boc})_{2} \mathrm{O}$ $(2.08 \mathrm{~g}, 9.55 \mathrm{mmol})$ and saturated aq. $\mathrm{NaHCO}_{3}$ until basic $\mathrm{pH}$ was reached. The mixture was stirred at room temperature for $18 \mathrm{~h}$, diluted with $10 \%$ aq. $\mathrm{HCl}(50 \mathrm{~mL})$, and extracted with EtOAc $(100 \mathrm{~mL})$. The organic layer was dried (anhydrous $\mathrm{Na}_{2} \mathrm{SO}_{4}$ ) and concentrated to dryness under reduced pressure. The crude product was purified by flash column chromatography (EtOAc/hexane 1:4) to give compound $19 \mathrm{~d}(0.80 \mathrm{~g}$, $1.43 \mathrm{mmol}, 75 \%$ yield $)$ as a yellowish oil. $[\alpha]_{\mathrm{D}}{ }^{23}=+37.0(c 1.6$, $\mathrm{CHCl}_{3}$ ). ${ }^{1} \mathrm{H} \mathrm{NMR}\left(250 \mathrm{MHz}, \mathrm{CDCl}_{3}, \mathrm{ppm}\right): \delta 1.41(\mathrm{~s}, 9 \mathrm{H})$, $3.16(\mathrm{dd}, 1 \mathrm{H}, J=6.0,4.1 \mathrm{~Hz}), 3.28(\mathrm{dd}, 1 \mathrm{H}, J=7.8,5.6 \mathrm{~Hz})$, $3.72(\mathrm{~s}, 3 \mathrm{H}), 3.80(\mathrm{dd}, 1 \mathrm{H}, J=7.8,7.1 \mathrm{~Hz}), 3.98(\mathrm{dd}, 1 \mathrm{H}, J=$ 5.6, $4.1 \mathrm{~Hz}), 4.18(\mathrm{dd}, 1 \mathrm{H}, J=7.1,6.0 \mathrm{~Hz}), 4.30-4.60(\mathrm{~m}$, $6 \mathrm{H}), 5.44$ (br, $1 \mathrm{H}), 7.28-7.38(\mathrm{~m}, 15 \mathrm{H}) .{ }^{13} \mathrm{C}\left\{{ }^{1} \mathrm{H}\right\}$ NMR $(62.5$ $\left.\mathrm{MHz}, \mathrm{CDCl}_{3}, \mathrm{ppm}\right): \delta$ 29.0, 52.4, 54.2, 54.7, 72.0, 72.4, 72.7, 74.7, 80.0, 83.3, 84.8, 127.1, 127.2, 127.3, 127.4, 128.1, 128.2, 128.3, 137.0, 137.2, 138.7, 155.3, 174.2. MS (CI, $m / z, \%): 562$ $\left(12,[\mathrm{M}+\mathrm{H}]^{+}\right) ; 505(49) ; 91$ (100). IR $\left(\mathrm{NaCl}, \mathrm{cm}^{-1}\right): \nu 3348$ (br, $\mathrm{NH}$ ), 1751 (st, $\mathrm{C}=\mathrm{O}$ ). Anal. calc. for $\mathrm{C}_{33} \mathrm{H}_{39} \mathrm{NO}_{7}: \mathrm{C}$, 70.57; H, 7.00; N, 2.49. Found: C, 70.37; H, 6.92; N, 2.62.

Dipeptide 20a. $\mathrm{Ba}(\mathrm{OH})_{2} \cdot 8 \mathrm{H}_{2} \mathrm{O}(1.34 \mathrm{~g}, 4.26 \mathrm{mmol})$ was added to a solution of compound $19 \mathrm{~d}(0.80 \mathrm{~g}, 1.42 \mathrm{mmol})$ in a $1: 2 \mathrm{THF} / \mathrm{H}_{2} \mathrm{O}$ mixture $(15 \mathrm{~mL})$. The reaction was stirred at $\mathrm{rt}$. for $1 \mathrm{~h}$ and then neutralized with 50WX4-50 DOWEX resin, which was then filtered off and washed with $\mathrm{MeOH}$. The solvent was removed under vacuum on a rotary evaporator. A solution of the resulting solid residue, HATU $(0.57 \mathrm{~g}, 1.70$ $\mathrm{mmol})$, and DIEA $(0.72 \mathrm{~mL}, 4.26 \mathrm{mmol})$ in dry $\mathrm{CH}_{2} \mathrm{Cl}_{2}(10$
$\mathrm{mL})$ was stirred at rt. for $15 \mathrm{~min}$. HCl-Gly-OMe (0.20 g, 1.56 mmol) was then added, and the stirring was continued for 14 h. $\mathrm{CH}_{2} \mathrm{Cl}_{2}(15 \mathrm{~mL})$ was added, the mixture was washed with $10 \%$ aq. $\mathrm{HCl}(15 \mathrm{~mL})$, and the organic layer was dried (anhydrous $\mathrm{Na}_{2} \mathrm{SO}_{4}$ ) and concentrated to dryness under a vacuum. Column chromatography of the solid residue (EtOAc/hexane 1:1) led to the isolation of dipeptide 20a ( $0.33 \mathrm{~g}, 0.53 \mathrm{mmol}, 60 \%$ overall yield from compound $19 \mathrm{~d}$ ) as a colorless oil. $[\alpha]_{\mathrm{D}}{ }^{21}=+68.2\left(c 1.5, \mathrm{CHCl}_{3}\right) .{ }^{1} \mathrm{H} \operatorname{NMR}(250$ $\left.\mathrm{MHz}_{\mathrm{CDCl}}, \mathrm{ppm}\right): \delta 1.37(\mathrm{~s}, 9 \mathrm{H}), 3.18(\mathrm{dd}, 1 \mathrm{H}, J=5.8,4.0$ $\mathrm{Hz}), 3.27\left(\mathrm{dd}, 1 \mathrm{H}, J_{3}=7.8,5.6 \mathrm{~Hz}\right), 3.61(\mathrm{~s}, 3 \mathrm{H}), 3.77-3.96$ (m, 2H), 4.03 (s, 2H), $4.13(\mathrm{dd}, 1 \mathrm{H}, J=7.0,5.8 \mathrm{~Hz}), 4.28-$ $4.48(\mathrm{~m}, 6 \mathrm{H}), 5.67(\mathrm{br}, 1 \mathrm{H}), 6.91(\mathrm{br}, 1 \mathrm{H}), 7.28-7.41(\mathrm{~m}$, 15H). ${ }^{13} \mathrm{C}\left\{{ }^{1} \mathrm{H}\right\} \operatorname{NMR}\left(62.5 \mathrm{MHz}, \mathrm{CDCl}_{3}, \mathrm{ppm}\right): \delta 29.3,39.7$, 52.6, 54.2, 55.0, 72.2, 72.5, 73.6, 74.7, 80.7, 83.4, 85.4, 127.4, 128.3, 128.5, 128.6, 137.4, 137.7, 138.7, 157.3, 169.3, 172.5. MS (CI, $m / z, \%): 619\left(56,[\mathrm{M}+\mathrm{H}]^{+}\right) ; 588(64) ; 91$ (100). Anal. calc. for $\mathrm{C}_{35} \mathrm{H}_{42} \mathrm{~N}_{2} \mathrm{O}_{8}$ : C, 67.94; H, 6.84; N, 4.53. Found: C, $68.12 ; \mathrm{H}, 7.01 ; \mathrm{N}, 4.29$.

Tripeptide 21. TFA $(2 \mathrm{~mL})$ in THF $(5 \mathrm{~mL})$ was added to a solution of compound 20a $(0.33 \mathrm{~g}, 0.53 \mathrm{mmol})$, and the mixture was stirred at rt. for $1 \mathrm{~h}$. The solvent was then coevaporated with toluene $(3 \times 2 \mathrm{~mL})$ under a vacuum in a rotary evaporator. HATU $(0.21 \mathrm{~g}, 0.64 \mathrm{mmol})$ and DIEA $(0.27$ $\mathrm{mL}, 1.59 \mathrm{mmol})$ were added to a solution of Boc-Gly-OH $(0.10 \mathrm{~g}, 0.58 \mathrm{mmol})$ in dry $\mathrm{CH}_{2} \mathrm{Cl}_{2}(5 \mathrm{~mL})$, and the mixture was stirred at rt. for $15 \mathrm{~m}$. A solution of the crude amine from the previous transformation in $\mathrm{CH}_{2} \mathrm{Cl}_{2}(10 \mathrm{~mL})$ was added, and the resulting mixture was stirred at rt. for $10 \mathrm{~h}$. The reaction mixture was washed with $10 \%$ aq $\mathrm{HCl}(20 \mathrm{~mL})$, and the organic layer was dried (anhydrous $\mathrm{Na}_{2} \mathrm{SO}_{4}$ ), filtered, and concentrated to dryness under a vacuum. Column chromatography of the solid residue (EtOAc) provided pure tripeptide $\mathbf{2 1}$ $(0.20 \mathrm{~g}, 0.30 \mathrm{mmol}, 55 \%$ overall yield from compound $20 \mathrm{a}$ ) as a colorless oil. $[\alpha]_{\mathrm{D}}{ }^{18}=+21.7\left(c 1.1, \mathrm{CHCl}_{3}\right) .{ }^{1} \mathrm{H}$ NMR $(250$ $\left.\mathrm{MHz}, \mathrm{CDCl}_{3}, \mathrm{ppm}\right): \delta 1.37$ (s, 9H), 3.12-3.14 (m, 1H), 3.20 (dd, $1 \mathrm{H}, J=7.4,5.1 \mathrm{~Hz}), 3.66(\mathrm{~s}, 3 \mathrm{H}), 3.79-3.91(\mathrm{~m}, 2 \mathrm{H})$, 4.03-4.09 (m, 4H), 4.31-4.43 (m, 6H), 4.55 (br, $1 \mathrm{H}), 5.55$ (br, 1H), 6.93 (br, 1H), 6.96 (br, $1 \mathrm{H}), 7.27-7.39(\mathrm{~m}, 15 \mathrm{H})$. ${ }^{13} \mathrm{C}\left\{{ }^{1} \mathrm{H}\right\} \operatorname{NMR}\left(62.5 \mathrm{MHz}, \mathrm{CDCl}_{3}, \mathrm{ppm}\right): \delta 29.0,40.0,42.5$, 52.8, 55.3, 56.3, 72.0, 72.2, 72.6, 75.0, 81.1, 84.7, 85.3, 127.9, $128.5,128.7,128.9,138.3,138.6,139.0,156.9,166.0,169.8$, 172.2. MS (CI, $m / z, \%): 676$ (18); 569 (64); 91 (100). Anal. Calc. for $\mathrm{C}_{37} \mathrm{H}_{45} \mathrm{~N}_{3} \mathrm{O}_{9}$ : C, 65.76; H, 6.71; N, 6.22. Found: C, 65.59; H, 6.49; N, 5.98.

Synthesis of Pentapeptide 24. 2-(Trimethylsilyl)ethyl (3aR,4S,6aS)-4-methoxy-2,2-dimethyl-3a,6a-dihydro-4Hcyclopenta[d][1,3]dioxole-6-carboxylate (18e). A solution of $\operatorname{DCC}(0.12 \mathrm{~g}, 0.56 \mathrm{mmol})$ in $\mathrm{CH}_{2} \mathrm{Cl}_{2}(2.2 \mathrm{~mL})$ was added to a solution carboxylic acid $18 \mathrm{c}(0.11 \mathrm{~g}, 0.51 \mathrm{mmol}), 2$ (trimethylsilyl)ethanol (15 $\mu \mathrm{L}, 1.02 \mathrm{mmol})$, and DMAP (6 $\mathrm{mg}, 0.05 \mathrm{mmol})$ in $\mathrm{CH}_{2} \mathrm{Cl}_{2}(2.2 \mathrm{~mL})$, and the mixture was stirred at rt. for $12 \mathrm{~h}$. Water $(10 \mathrm{~mL})$ was then added, and the resulting mixture was extracted with $\mathrm{CH}_{2} \mathrm{Cl}_{2}(3 \times 10 \mathrm{~mL})$. The combined organic layers were washed with aq. saturated solution of $\mathrm{NaHCO}_{3}(20 \mathrm{~mL})$ and brine $(20 \mathrm{~mL})$, dried (anhydrous $\mathrm{Na}_{2} \mathrm{SO}_{4}$ ), filtered, and evaporated under reduced pressure. The residue was purified by flash column chromatography (EtOAc/hexane 1:7) to obtain ester 18e $(0.13 \mathrm{~g}, 77 \%)$ as a clear oil. $[\alpha]_{\mathrm{D}}{ }^{22}=+34.5\left(c 0.5, \mathrm{CHCl}_{3}\right) .{ }^{1} \mathrm{H}$ $\mathrm{NMR}\left(\mathrm{CDCl}_{3}, 300 \mathrm{MHz}, \mathrm{ppm}\right): \delta 0.05\left(\mathrm{~s}, 9 \mathrm{H}, 3 \times \mathrm{CH}_{3}\right)$, 0.88-1.19 (m, 2H, $\left.\mathrm{CH}_{2} \mathrm{Si}\right), 1.37\left(\mathrm{~s}, 3 \mathrm{H}, \mathrm{CH}_{3}\right), 1.41(\mathrm{~s}, 3 \mathrm{H}$, $\mathrm{CH}_{3}$ ), 3.45 (s, 3H, OMe), 4.21-4.38 (m, $\left.2 \mathrm{H}, \mathrm{CH}_{2} \mathrm{O}\right), 4.40$ 
(td, $1 \mathrm{H}, J=2.1,1.0 \mathrm{~Hz}, \mathrm{H}-4), 4.61(\mathrm{dt}, 1 \mathrm{H}, J=6.0,1.0 \mathrm{~Hz}, \mathrm{H}-$ 3a), 5.42 (dd, $1 \mathrm{H}, J=6.0,1.8 \mathrm{~Hz}, \mathrm{H}-6 \mathrm{a}), 6.71$ (dd, $1 \mathrm{H}, J=2.1$, $0.8 \mathrm{~Hz}, \mathrm{H}-5) .{ }^{13} \mathrm{C}\left\{{ }^{1} \mathrm{H}\right\} \mathrm{NMR}\left(\mathrm{CDCl}_{3}, 75 \mathrm{MHz}, \mathrm{ppm}\right): \delta-1.4$, 17.4, 25.4, 27.2, 57.5, 63.4, 82.6, 83.4, 89.3, 112.6, 141.4, 145.7, 163.9. IR $\left(\mathrm{NaCl}, \mathrm{cm}^{-1}\right): \nu 1720$ (st, $\mathrm{C}=\mathrm{O}$ ). HRMS (ESI+): calc. for $\mathrm{C}_{15} \mathrm{H}_{26} \mathrm{O}_{5} \mathrm{Si}(\mathrm{M}+\mathrm{Na})^{+} 337.1442$, found 337.1447.

2-(Trimethylsilyl)ethyl (3aS,4R,5R,6S,6aS)-5-(benzylamino)-6-methoxy-2,2-dimethyltetrahydro-4H-cyclopenta[d]$[1,3]$ dioxole-4-carboxylate (19f). Benzylamine (18 $\mu \mathrm{L}, 0.16$ $\mathrm{mmol})$ was added to a solution of ester $18 \mathrm{e}(42 \mathrm{mg}, 0.134$ $\mathrm{mmol})$ in DMF $(0.4 \mathrm{~mL})$, and the resulting mixture was stirred at $\mathrm{rt}$. for $60 \mathrm{~h}$ when the solvents were removed under reduced pressure. The resulting residue was taken up in EtOAc (10 $\mathrm{mL})$, washed with water $(3 \times 5 \mathrm{~mL})$, dried (anhydrous $\mathrm{Na}_{2} \mathrm{SO}_{4}$ ), and filtered, and the solvent was evaporated under reduced pressure. The residue was purified by flash column chromatography (EtOAc/hexane 1:3), to obtain compound 19f $(39 \mathrm{mg}, 69 \%)$ as a clear oil. $[\alpha]_{\mathrm{D}}^{22}=-5.4\left(c 3.4, \mathrm{CHCl}_{3}\right)$. ${ }^{1} \mathrm{H}$ NMR $\left(\mathrm{CDCl}_{3}, 300 \mathrm{MHz}, \mathrm{ppm}\right): \delta 0.04\left(\mathrm{~s}, 9 \mathrm{H}, 3 \times \mathrm{CH}_{3}\right)$, 0.99 (ddd, $2 \mathrm{H}, J=9.1,7.1,1.0 \mathrm{~Hz}, \mathrm{CH}_{2}-\mathrm{Si}$ ), 1.30 (s, $3 \mathrm{H}, \mathrm{CH}_{3}$ ), 1.48 (s, 3H, $\mathrm{CH}_{3}$ ), 1.92 (s, 1H, NH), 2.88 (dd, 1H, J = 9.1, 5.3 $\mathrm{Hz}, \mathrm{H}-4), 3.37-3.47$ (m, 4H, OMe + H-5), 3.65 (dd, 1H, J = 7.2, $3.3 \mathrm{~Hz}, \mathrm{H}-6$ ), 3.82 (d, $2 \mathrm{H}, J=2.5 \mathrm{~Hz}, \mathrm{CH}_{2} \mathrm{Bn}$ ), 4.19 (ddd, $\left.2 \mathrm{H}, J=9.2,7.1,1.0 \mathrm{~Hz}, \mathrm{CH}_{2}-\mathrm{O}\right), 4.42(\mathrm{dd}, 1 \mathrm{H}, J=7.3,3.3 \mathrm{~Hz}$, H-6a), 4.84 (dd, $1 \mathrm{H}, J=7.3,5.3 \mathrm{~Hz}, \mathrm{H}-3 \mathrm{a}), 7.18-7.37$ (m, 5H, $5 \times \mathrm{H}-\mathrm{Ar}) .{ }^{13} \mathrm{C}\left\{{ }^{1} \mathrm{H}\right\} \mathrm{NMR}\left(\mathrm{CDCl}_{3}, 75 \mathrm{MHz}, \mathrm{ppm}\right): \delta-1.4$, 17.5, 24.8, 27.1, 51.7, 54.1, 57.7, 63.6, 65.1, 79.8, 83.2, 90.1, $112.5,127.1,128.3,128.5,140.2,172.9$. IR $\left(\mathrm{NaCl}, \mathrm{cm}^{-1}\right): \nu$ 3350 (br, NH); 1726 (st, C=O). HRMS (ESI+) $m / z(\mathrm{M}+$ $\mathrm{H})^{+}$calc. for $\mathrm{C}_{22} \mathrm{H}_{36} \mathrm{O}_{5} \mathrm{Si}$ 422.2357. Found 422.2360.

Tripeptide 23a. A $1 \mathrm{M}$ solution of TBAF in THF $(0.17 \mathrm{~mL})$ was added to a solution of amino acid ester $19 \mathrm{f}(65 \mathrm{mg}, 0.154$ $\mathrm{mmol})$ in THF ( $3 \mathrm{~mL})$, and the resulting mixture was stirred at rt. for $24 \mathrm{~h}$. The reaction mixture was diluted with aq. saturated solution of $\mathrm{NH}_{4} \mathrm{Cl}(5 \mathrm{~mL})$ and extracted with ethyl acetate (3 $\times 5 \mathrm{~mL}$ ). The combined organic layers were dried (anhydrous $\mathrm{Na}_{2} \mathrm{SO}_{4}$ ) and filtered, and the solvent was evaporated under reduced pressure. The resulting crude of $19 \mathrm{~g}$ was dissolved in dry DMF (4 mL), and then PyBOP (104 mg, $0.200 \mathrm{mmol}$ ) and $\mathrm{HOBt} . \mathrm{H}_{2} \mathrm{O}(31 \mathrm{mg}, 0.200 \mathrm{mmol})$ were added. After 10 min at rt., ACPC dimer 22a (54 mg, $0.185 \mathrm{mmol}$ ) and DIEA $(110 \mu \mathrm{L}, 0.616 \mathrm{mmol})$ were added, and the reaction mixture was stirred overnight at $\mathrm{rt}$. The reaction was then diluted with $\mathrm{CH}_{2} \mathrm{Cl}_{2}(20 \mathrm{~mL})$ and washed with $1 \mathrm{M} \mathrm{HCl}(20 \mathrm{~mL})$, aq. saturated solution of $\mathrm{NaHCO}_{3}(20 \mathrm{~mL})$, and brine $(20 \mathrm{~mL})$. The organic layer was dried (anhydrous $\mathrm{Na}_{2} \mathrm{SO}_{4}$ ), filtered, and concentrated under reduced pressure. The obtained residue was purified by flash column chromatography (EtOAc) to yield compound $23 \mathrm{a}$ (37 mg, 43\%) as a white solid. $[\alpha]_{\mathrm{D}}^{22}=+29.1$ (c 2.0, $\left.\mathrm{CHCl}_{3}\right) .{ }^{1} \mathrm{H} \mathrm{NMR}\left(\mathrm{CDCl}_{3}, 300 \mathrm{MHz}, \mathrm{ppm}\right): \delta 1.22-$ $1.45\left(\mathrm{~m}, 4 \mathrm{H}, \mathrm{CH}_{3}+\mathrm{CH}_{2}\right), 1.51\left(\mathrm{~s}, 3 \mathrm{H}, \mathrm{CH}_{3}\right), 1.53-1.79(\mathrm{~m}$, $\left.5 \mathrm{H}, 2 \times \mathrm{CH}_{2}+\mathrm{CH}_{2}\right), 1.83-2.27\left(\mathrm{~m}, 7 \mathrm{H}, 3 \times \mathrm{CH}_{2}+\mathrm{NH}\right), 2.47$ (dd, $1 \mathrm{H}, J=8.4,4.5 \mathrm{~Hz}, \mathrm{C} \underline{\mathrm{H}}-\mathrm{CO}), 2.56-2.68(\mathrm{~m}, 2 \mathrm{H}, 2 \times \mathrm{C} \underline{\mathrm{H}}-$ CO), 3.22 (dd, $1 \mathrm{H}, J=11.9,8.6 \mathrm{~Hz}, \mathrm{CH}-\mathrm{N}), 3.47$ (s, $3 \mathrm{H}$, OMe), 3.59-3.71 (m, 4H, OMe + $\underline{\mathrm{H}}-\mathrm{N}), 3.83(\mathrm{~d}, 1 \mathrm{H}, J=$ $\left.13.9 \mathrm{~Hz}, \mathrm{CH}_{2} \mathrm{Bn}\right), 3.96\left(\mathrm{~d}, J=12.9 \mathrm{~Hz}, 1 \mathrm{H}, \mathrm{CH}_{2} \mathrm{Bn}\right), 4.11(\mathrm{t}, J$ $=6.3 \mathrm{~Hz}, 1 \mathrm{H}, \mathrm{CH}-\mathrm{N}), 4.30-4.41(\mathrm{~m}, 2 \mathrm{H}, 2 \times \mathrm{CH}-\mathrm{O}), 4.79(\mathrm{t}$, $1 \mathrm{H}, J=7.1 \mathrm{~Hz}, \mathrm{CH}-\mathrm{O}), 7.30(\mathrm{td}, 5 \mathrm{H}, J=9.6,8.6,3.6 \mathrm{~Hz}, 5 \times$ $\mathrm{H}-\mathrm{Ar}$ ), 7.65 (d, $1 \mathrm{H}, J=6.3 \mathrm{~Hz}, \mathrm{NH}), 7.92(\mathrm{~d}, 1 \mathrm{H}, J=7.1 \mathrm{~Hz}$, $\mathrm{NH}) .{ }^{13} \mathrm{C}\left\{{ }^{1} \mathrm{H}\right\}$ NMR $\left(\mathrm{CDCl}_{3}, 75 \mathrm{MHz}, \mathrm{ppm}\right): \delta$ 23.1, 24.8, $24.9,27.2,27.3,28.4,32.8,33.3,50.4,50.7,52.0,52.4,53.2$, 54.9, 56.1, 57.8, 63.8, 77.4, 82.0, 90.4 (CH), 113.1, 127.6, $128.3,128.7,139.3,172.5,173.3,175.6 . \mathrm{IR}\left(\mathrm{NaCl}, \mathrm{cm}^{-1}\right): \nu$
3287 (br, NH); 1732, 1643 (st, C=O). HRMS (ESI+) $m / z(\mathrm{M}$ $+\mathrm{H})^{+}$calc. for $\mathrm{C}_{30} \mathrm{H}_{44} \mathrm{~N}_{3} \mathrm{O}_{7}$ 558.3174. Found 558.3174.

Pentapeptide 24. $20 \% \mathrm{Pd}(\mathrm{OH})_{2} / \mathrm{C}(12 \mathrm{mg})$ was added over a deoxygenated solution of compound 23a (23 mg, 0.041 $\mathrm{mmol})$ in methanol $(4 \mathrm{~mL})$, and the resulting suspension was deoxygenated again and stirred overnight under a hydrogen atmosphere $(P=1 \mathrm{~atm})$. The reaction was filtered through Celite and washed with methanol, and the filtrate was evaporated to dryness under a vacuum to give chromatographically pure 23b. PyBOP (28 mg, $0.054 \mathrm{mmol}$ ), HOBt ( 8 $\mathrm{mg}, 0.054 \mathrm{mmol})$, and DIEA $(0.28 \mathrm{~mL}, 1.59 \mathrm{mmol})$ were added over a solution of ACPC dimer $22 b(20 \mathrm{mg}, 0.054$ $\mathrm{mmol})$ in dry DMF ( $1 \mathrm{~mL})$. After 5 min stirring, a solution of the crude of $\mathbf{2 3 b}$ in dry DMF ( $1 \mathrm{~mL}$ ) was added to the other solution, and the reaction mixture was stirred at rt. overnight. Then, the reaction mixture was diluted with $\mathrm{CH}_{2} \mathrm{Cl}_{2}(10 \mathrm{~mL})$ and washed with $1 \mathrm{M} \mathrm{HCl}(10 \mathrm{~mL})$, aq. saturated solution of $\mathrm{NaHCO}_{3}(10 \mathrm{~mL})$, and brine $(10 \mathrm{~mL})$. The organic layer was dried (anhydrous $\mathrm{Na}_{2} \mathrm{SO}_{4}$ ), filtered, and concentrated under reduced pressure. The obtained residue was purified by flash column chromatography (EtOAc/hexane 4:1) to obtain pentamer $24(20 \mathrm{mg}, 59 \%)$ as a white solid. $[\alpha]_{\mathrm{D}}{ }^{22}=+47.7$ (c 1.0, $\left.\mathrm{CHCl}_{3}\right) .{ }^{1} \mathrm{H} \mathrm{NMR}\left(\mathrm{CDCl}_{3}, 300 \mathrm{MHz}, \mathrm{ppm}\right): \delta 1.27$ (s, $\left.3 \mathrm{H}, \mathrm{CH}_{3}\right), 1.31\left(\mathrm{~s}, 3 \mathrm{H}, \mathrm{CH}_{3}\right), 1.55-1.81\left(\mathrm{~m}, 12 \mathrm{H}, \mathrm{CH}_{2}\right)$, 1.90-2.17 (m, 13H, CH $\left.{ }_{2}+\mathrm{C} \underline{H}-\mathrm{CO}\right), 2.38-2.49(\mathrm{~m}, 1 \mathrm{H}, \mathrm{C} \underline{\mathrm{H}}-$ CO), $2.62(\mathrm{dd}, J=9.5,4.1 \mathrm{~Hz}, 2 \mathrm{H}, \mathrm{C} \underline{\mathrm{H}}-\mathrm{CO}), 2.89-3.04(\mathrm{~m}$, $1 \mathrm{H}, \mathrm{C} \underline{\mathrm{H}}-\mathrm{CO}$ ), 3.45 (s, 3H, OMe $), 3.66$ (s, 3H, OMe), 3.85 $(\mathrm{dd}, J=9.8,5.4 \mathrm{~Hz}, 1 \mathrm{H}, \mathrm{C} \underline{\mathrm{H}}-\mathrm{N}), 4.08-4.22(\mathrm{~m}, 3 \mathrm{H}, \mathrm{CH}-\mathrm{N}+$ $\mathrm{CH}-\mathrm{O}), 4.33(\mathrm{q}, J=9.1,8.6 \mathrm{~Hz}, 2 \mathrm{H}, \mathrm{CH}-\mathrm{N}), 4.41-4.51(\mathrm{~m}$, $2 \mathrm{H}, \mathrm{CH}-\mathrm{O}$ ), 5.00 (dd, $J=7.2,4.3 \mathrm{~Hz}, 1 \mathrm{H}, \mathrm{CH}-\mathrm{O}$ ), 5.12 (dd, $J$ $\left.=12.3,16.7 \mathrm{~Hz}, 2 \mathrm{H}, \mathrm{CH}_{2}-\mathrm{Ar}\right), 5.89(\mathrm{~d}, J=7.9 \mathrm{~Hz}, 1 \mathrm{H}, \mathrm{NH})$, 6.47 (d, J = 8.4 Hz, 1H, NH), 7.36 (s, 5H, CH $-\underline{\text { Ar }}$ ), 7.69 (d, J $=8.1 \mathrm{~Hz}, 1 \mathrm{H}, \mathrm{NH}), 8.13-8.48(\mathrm{~m}, 2 \mathrm{H}, \mathrm{NH}) .{ }^{13} \mathrm{C}\left\{{ }^{1} \mathrm{H}\right\} \mathrm{NMR}$ $\left(\mathrm{CDCl}_{3}, 75 \mathrm{MHz}, \mathrm{ppm}\right): \delta$ 23.6, 24.1, 24.4, 25.4, 25.5, 27.6, $28.3,28.9,29.0,29.8,32.5,33.6,33.9,50.2,51.8,51.9,53.1$, 53.5, 54.7, 55.0, 55.6, 55.7, 57.7, 57.9, 58.0, 67.0, 78.9, 82.5, $89.4,112.5,127.9,128.4,128.8,136.4,156.8,171.2,174.3$, 174.6, 175.1, 176.6. IR (ATR, cm $\left.{ }^{-1}\right): \nu 3289(\mathrm{NH}), 3037$ $(\mathrm{NH}), 1699(\mathrm{C}=\mathrm{O}), 1645(\mathrm{C}=\mathrm{O}), 1555(\mathrm{C}=\mathrm{O})$. HRMS (ESI +) $m / z(\mathrm{M}+\mathrm{Na})^{+}$calc. for $\mathrm{C}_{43} \mathrm{H}_{61} \mathrm{~N}_{5} \mathrm{NaO}_{11}$ 846.4260. Found 846.4262 .

\section{ASSOCIATED CONTENT}

\section{SI Supporting Information}

The Supporting Information is available free of charge at https://pubs.acs.org/doi/10.1021/acsomega.1c05468.

Copies of ${ }^{1} \mathrm{H},{ }^{13} \mathrm{C}\left\{{ }^{1} \mathrm{H}\right\}$, and DEPT-135 NMR spectra for compounds $7 b, 8,9 a, 9 b, 9 c, 10,11 b, 12,13 c, 13 d, 14 a$, $14 b, 15 a, 15 b, 16 a, 16 b, 16 c, 16 d, 17 a, 17 b, 18 b, 18 d$, 18e, 19a, 19b, 19d, 19f, 20a, 21, 23a, and 24 (PDF)

\section{AUTHOR INFORMATION}

\section{Corresponding Author}

Juan C. Estévez - Centro Singular de Investigación en Química Biolóxica e Materiais Moleculares (CIQUS), Universidade de Santiago de Compostela, 15782 Santiago de Compostela, Spain; Departamento de Química Orgánica, Universidade de Santiago de Compostela, 15782 Santiago de Compostela, Spain; 이이.org/0000-0001-9468-9045; Phone: (+34) 881815 730; Email: juancarlos.estevez@ usc.es 


\section{Authors}

Fernando Fernández - Centro Singular de Investigación en Química Biolóxica e Materiais Moleculares (CIQUS), Universidade de Santiago de Compostela, 15782 Santiago de Compostela, Spain

Alberto G. Fernández - Centro Singular de Investigación en Química Biolóxica e Materiais Moleculares (CIQUS), Universidade de Santiago de Compostela, 15782 Santiago de Compostela, Spain

Rosalino Balo - Centro Singular de Investigación en Química Biolóxica e Materiais Moleculares (CIQUS), Universidade de Santiago de Compostela, 15782 Santiago de Compostela, Spain

Víctor M. Sánchez-Pedregal - Departamento de Química Orgánica, Universidade de Santiago de Compostela, 15782 Santiago de Compostela, Spain; (1) orcid.org/0000-00031581-0455

Miriam Royo - Centro de Investigación Biomédica en Red Bioingeniería, Biomateriales y Nanomedicina (CIBER-BBN), 08034 Barcelona, Spain; Instituto de Química Avanzada de Cataluña (IQAC-CSIC), 08034 Barcelona, Spain; (1) orcid.org/0000-0001-5292-0819

Raquel G. Soengas - Departamento de Química Orgánica e Inorgánica, Universidad de Oviedo, 33006 Oviedo, Spain; (1) orcid.org/0000-0001-8178-0034

Ramón J. Estévez - Centro Singular de Investigación en Química Biolóxica e Materiais Moleculares (CIQUS), Universidade de Santiago de Compostela, 15782 Santiago de Compostela, Spain; Departamento de Química Orgánica, Universidade de Santiago de Compostela, 15782 Santiago de Compostela, Spain; (1) orcid.org/0000-0002-3764-0832

Complete contact information is available at:

https://pubs.acs.org/10.1021/acsomega.1c05468

\section{Notes}

The authors declare no competing financial interest.

\section{ACKNOWLEDGMENTS}

This work has received financial support from the European Union (European Regional Development Fund - ERDF), the Spanish Ministerio de Economía y Competitividad (SAF201460138-R), the CIBER BBN (CB/06/01/0074), the Xunta de Galicia (Centro Singular de Investigación de Galicia accreditation 2019-2022, ED431G 2019/03; and grants ED431C 2018/30 and ED431C 2018/04), the Generalitat de Catalunya (2017-SGR-1439), and the Galchimia S.A. (Spain). R.B. and F.F. thank the Ministerio de Educación, Cultura y Deporte and the Ministerio de Educación y Ciencia, respectively, for FPU fellowships.

\section{REFERENCES}

(1) Enantioselective Synthesis of Beta-Amino Acids, 2nd ed.; Juaristi, E.; Soloshonok, V. A., Eds.; Wiley: Hoboken, N.J, 2005.

(2) Weiner, B.; Szymański, W.; Janssen, D. B.; Minnaard, A. J.; Feringa, B. L. Recent Advances in the Catalytic Asymmetric Synthesis of $\beta$-Amino Acids. Chem. Soc. Rev. 2010, 39, 1656.

(3) Kiss, L.; Fülöp, F. Synthesis of Carbocyclic and Heterocyclic $\beta$ Aminocarboxylic Acids. Chem. Rev. 2014, 114, 1116-1169.

(4) Grygorenko, O. O. Bicyclic $\beta$-Amino Acids. Tetrahedron 2015, $71,5169-5216$.

(5) Ashfaq, M.; Tabassum, R.; Ahmad, M. M.; Hassan, N. A.; Oku, H.; Rivera, G. Enantioselective Synthesis of $\beta$-Amino Acids: A Review. Med. Chem. 2015, 5, 295-309.
(6) Gellman, S. H. Foldamers: A Manifesto. Acc. Chem. Res. 1998, $31,173-180$

(7) Guichard, G. $\beta$-Peptides, $\gamma$-Peptides and Isosteric Backbones: New Scaffolds with Controlled Shapes for Mimicking Protein Secondary Structure Elements. In Pseudo-Peptides in Drug Development; Nielsen, P. E., Ed.; Wiley-VCH Verlag GmbH \& Co. KGaA: Weinheim, FRG, 2005; pp. 33-120, DOI: 10.1002/3527601902.ch2. (8) Aguilar, M.-I.; Purcell, A. W.; Devi, R.; Lew, R.; Rossjohn, J.; Smith, A. I.; Perlmutter, P. $\beta$-Amino Acid-Containing Hybrid Peptides-New Opportunities in Peptidomimetics. Org. Biomol. Chem. 2007, 5, 2884.

(9) Seebach, D.; Gardiner, J. $\beta$-Peptidic Peptidomimetics. Acc. Chem. Res. 2008, 41, 1366-1375.

(10) Chand, P.; Kotian, P. L.; Dehghani, A.; El-Kattan, Y.; Lin, T.H.; Hutchison, T. L.; Babu, Y. S.; Bantia, S.; Elliott, A. J.; Montgomery, J. A. Systematic Structure-Based Design and Stereoselective Synthesis of Novel Multisubstituted Cyclopentane Derivatives with Potent Antiinfluenza Activity. J. Med. Chem. 2001, 44, 4379-4392.

(11) Hook, D. F.; Bindschädler, P.; Mahajan, Y. R.; Šebesta, R.; Kast, P.; Seebach, D. The Proteolytic Stability of 'Designed' $\beta$-Peptides Containing $\alpha$-Peptide-Bond Mimics and of Mixed $\alpha, \beta$-Peptides: Application to the Construction of MHC-Binding Peptides. Chem. Biodiversity 2005, 2, 591-632.

(12) Heck, T.; Limbach, M.; Geueke, B.; Zacharias, M.; Gardiner, J.; Kohler, H.-P. E.; Seebach, D. Enzymatic Degradation of $\beta$ - and Mixed $\alpha, \beta$-Oligopeptides. Chem. Biodiversity 2006, 3, 1325-1348.

(13) Katoh, T.; Sengoku, T.; Hirata, K.; Ogata, K.; Suga, H. Ribosomal Synthesis and de Novo Discovery of Bioactive Foldamer Peptides Containing Cyclic $\beta$-Amino Acids. Nat. Chem. 2020, 12, 1081-1088.

(14) Gentilucci, L.; De Marco, R.; Cerisoli, L. Chemical Modifications Designed to Improve Peptide Stability: Incorporation of Non-Natural Amino Acids, Pseudo-Peptide Bonds, and Cyclization. Curr. Pharm. Des. 2010, 16, 3185-3203.

(15) Gopalan, R. D.; Del Borgo, M. P.; Mechler, A. I.; Perlmutter, P.; Aguilar, M.-I. Geometrically Precise Building Blocks: The SelfAssembly of $\beta$-Peptides. Chem. Biol. 2015, 22, 1417-1423.

(16) Fülöp, F. The Chemistry of 2-Aminocycloalkanecarboxylic Acids. Chem. Rev. 2001, 101, 2181-2204.

(17) Miller, J.; Nguyen, S. The Enantioselective Synthesis of Conformationally Constrained Cyclic $\beta$-Amino Acids. Mini-Rev. Org. Chem. 2005, 2, 39-45.

(18) Appella, D. H.; Christianson, L. A.; Karle, I. L.; Powell, D. R.; Gellman, S. H. $\beta$-Peptide Foldamers: Robust Helix Formation in a New Family of $\beta$-Amino Acid Oligomers. J. Am. Chem. Soc. 1996, 118, 13071-13072.

(19) Benedek, G.; Palkó, M.; Wéber, E.; Martinek, T. A.; Forró, E.; Fülöp, F. Efficient Synthesis of Hydroxy-Substituted Cispentacin Derivatives: Synthesis of Hydroxy-Substituted Cispentacin Derivatives. Eur. J. Org. Chem. 2008, 2008, 3724-3730.

(20) Abraham, E.; Claridge, T. D. W.; Davies, S. G.; Odell, B.; Roberts, P. M.; Russell, A. J.; Smith, A. D.; Smith, L. J.; Storr, H. R.; Sweet, M. J.; Thompson, A. L.; Thomson, J. E.; Tranter, G. E.; Watkin, D. J. A Systematic Study of the Solid State and Solution Phase Conformational Preferences of $\beta$-Peptides Derived from C(3)Alkyl Substituted Transpentacin Derivatives. Tetrahedron: Asymmetry 2011, 22, 69-100.

(21) Martinek, T. A.; Tóth, G. K.; Vass, E.; Hollósi, M.; Fülöp, F. Cis-2-Aminocyclopentanecarboxylic Acid Oligomers Adopt a Sheetlike Structure: Switch from Helix to Nonpolar Strand. Angew. Chem., Int. Ed Engl. 2002, 41, 1718-1721.

(22) Martinek, T. A.; Mándity, I. M.; Fülöp, L.; Tóth, G. K.; Vass, E.; Hollósi, M.; Forró, E.; Fülöp, F. Effects of the Alternating Backbone Configuration on the Secondary Structure and SelfAssembly of $\beta$-Peptides. J. Am. Chem. Soc. 2006, 128, 13539-13544.

(23) Sussman, F.; Sánchez-Pedregal, V. M.; Estévez, J. C.; Balo, R.; Jiménez-Barbero, J.; Ardá, A.; Gimeno, A.; Royo, M.; Villaverde, M. C.; Estévez, R. J. Environmental Effects Determine the Structure of 
Potential $\beta$-Amino Acid Based Foldamers. Chem. - Eur. J. 2018, 24, $10625-10629$

(24) Wang, Y.; Xing, Y.; Liu, X.; Ji, H.; Kai, M.; Chen, Z.; Yu, J.; Zhao, D.; Ren, H.; Wang, R. A New Class of Highly Potent and Selective Endomorphin-1 Analogues Containing $\alpha$-Methylene- $\beta$ Aminopropanoic Acids (Map). J. Med. Chem. 2012, 55, 6224-6236.

(25) Keresztes, A.; Szǘcs, M.; Borics, A.; Kövér, K. E.; Forró, E.; Fülöp, F.; Tömböly, C.; Péter, A.; Páhi, A.; Fábián, G.; Murányi, M.; Tóth, G. New Endomorphin Analogues Containing Alicyclic $\beta$-Amino Acids: Influence on Bioactive Conformation and Pharmacological Profile. J. Med. Chem. 2008, 51, 4270-4279.

(26) Kwon, S.; Jeon, A.; Yoo, S. H.; Chung, I. S.; Lee, H.-S. Unprecedented Molecular Architectures by the Controlled SelfAssembly of a $\beta$-Peptide Foldamer. Angew. Chem., Int. Ed. 2010, 49, 8232-8236.

(27) Gong, J.; Eom, T.; Lee, W.; Roy, A.; Kwon, S.; Kim, H.; Lee, H.-S. Self-Assembly of a B-Peptide Foldamer: The Role of the Surfactant in Three-Dimensional Shape Selection. ChemPlusChem 2019, 84, 481-487.

(28) Hubbard, R. D.; Miller, B. L. Regioselective and Diastereoselective Synthesis of Highly Substituted Cyclopentanes. Tetrahedron 2003, 59, 8143-8152.

(29) Heasley, B. Stereocontrolled Preparation of Fully Substituted Cyclopentanes: Relevance to Total Synthesis. Eur. J. Org. Chem. 2009, 2009, 1477-1489.

(30) Parr, B. T.; Davies, H. M. L. Highly Stereoselective Synthesis of Cyclopentanes Bearing Four Stereocentres by a Rhodium CarbeneInitiated Domino Sequence. Nat. Commun. 2014, 5, 4455.

(31) Tan, B.; Chua, P. J.; Zeng, X.; Lu, M.; Zhong, G. A Highly Diastereo- and Enantioselective Synthesis of Multisubstituted Cyclopentanes with Four Chiral Carbons by the Organocatalytic Domino Michael-Henry Reaction. Org. Lett. 2008, 10, 3489-3492.

(32) Risseeuw, M.; Overhand, M.; Fleet, G. W. J.; Simone, M. I. A Compendium of Cyclic Sugar Amino Acids and Their Carbocyclic and Heterocyclic Nitrogen Analogues. Amino Acids 2013, 45, 613689.

(33) Kiss, L.; Mándity, I. M.; Fülöp, F. Highly Functionalized Cyclic $\beta$-Amino Acid Moieties as Promising Scaffolds in Peptide Research and Drug Design. Amino Acids 2017, 49, 1441-1455.

(34) Martínez, R. F.; Jenkinson, S. F.; Nakagawa, S.; Kato, A.; Wormald, M. R.; Fleet, G. W. J.; Hollinshead, J.; Nash, R. J. Isolation from Stevia Rebaudiana of DMDP Acetic Acid, a Novel Iminosugar Amino Acid: Synthesis and Glycosidase Inhibition Profile of Glycine and $\beta$-Alanine Pyrrolidine Amino Acids. Amino Acids 2019, 51, 991998.

(35) Soengas, R.; Lorca, M.; Pampín, B.; Sánchez-Pedregal, V. M.; Estévez, R. J.; Estévez, J. C. New Morphiceptin Peptidomimetic Incorporating (1S,2R,3S,4S,5R)-2-Amino-3,4,5-TrihydroxycyclopenTane-1-Carboxylic Acid: Synthesis and Structural Study. Molecules 2020, 25, 2574

(36) Gu, X.; Gupta, V.; Yang, Y.; Zhu, J.-Y.; Carlson, E. J.; Kingsley, C.; Tash, J. S.; Schönbrunn, E.; Hawkinson, J.; Georg, G. I. StructureActivity Studies of $N$-Butyl-1-Deoxynojirimycin ( $N$ B-DNJ) Analogues: Discovery of Potent and Selective Aminocyclopentitol Inhibitors of GBA1 and GBA2. ChemMedChem 2017, 12, 1977-1984.

(37) Schalli, M.; Tysoe, C.; Fischer, R.; Pabst, B. M.; Thonhofer, M.; Paschke, E.; Rappitsch, T.; Stütz, A. E.; Tschernutter, M.; Windischhofer, W.; Withers, S. G. N-Substituted 5-Amino-1Hydroxymethyl-Cyclopentanetriols: A New Family of Activity Promotors for a G M1 -Gangliosidosis Related Human Lysosomal $\beta$-Galactosidase Mutant. Carbohydr. Res. 2017, 443-444, 15-22.

(38) Schalli, M.; Weber, P.; Tysoe, C.; Pabst, B. M.; Thonhofer, M.; Paschke, E.; Stütz, A. E.; Tschernutter, M.; Windischhofer, W.; Withers, S. G. A New Type of Pharmacological Chaperone for G M1 -Gangliosidosis Related Human Lysosomal $\beta$-Galactosidase: $N$ -Substituted 5-Amino-1-Hydroxymethyl-Cyclopentanetriols. Bioorg. Med. Chem. Lett. 2017, 27, 3431-3435.

(39) Soengas, R. G.; Estévez, J. C.; Estévez, R. J. Stereocontrolled Transformation of Nitrohexofuranoses into Cyclopentylamines via 2-
Oxabicyclo[2.2.1]Heptanes: Incorporation of Polyhydroxylated Carbocyclic $\beta$-Amino Acids into Peptides. Org. Lett. 2003, 5, 1423-1425.

(40) Fernández, F.; Pampín, B.; González, M. A.; Estévez, J. C.; Estévez, R. J. Stereocontrolled Transformation of Nitrohexofuranoses into Cyclopentylamines via 2-Oxabicyclo[2.2.1] Heptanes. Part VI: Synthesis and Incorporation of the Novel Polyhydroxylated 5Aminocyclopent-1-Enecarboxylic Acids into Peptides. Tetrahedron: Asymmetry 2010, 21, 2021-2026.

(41) Soengas, R. G.; Pampín, M. B.; Estévez, J. C.; Estévez, R. J. Stereocontrolled Transformation of Nitrohexofuranoses into Cyclopentylamines via 2-Oxabicyclo[2.2.1] Heptanes. Part 2: Synthesis of (1S,2R,3S,4S,5R)-3,4,5-Trihydroxy-2-Aminocyclopentanecarboxylic Acid. Tetrahedron: Asymmetry 2005, 16, 205-211.

(42) Soengas, R. G.; Estévez, A. M.; Estévez, J. C.; Estévez, R. J. An Overview on the Synthesis of Furanoid and Pyranoid Sugar $\alpha$ - and $\beta$ Amino Acids and Related Aminocycloalkanecarboxylic Acids from Carbohydrates. C. R. Chim. 2011, 14, 313-326.

(43) Vougioukalakis, G. C.; Grubbs, R. H. Ruthenium-Based Heterocyclic Carbene-Coordinated Olefin Metathesis Catalysts. Chem. Rev. 2010, 110, 1746-1787.

(44) Perlmutter, P.; Tabone, M. A Simple Route to .Alpha.Substituted-.Beta.-Amino Ester Precursors of Carbapenem Antibiotics. J. Org. Chem. 1995, 60, 6515-6522.

(45) An initial version of this work was deposited in ChemRxiv on August 02, 2021, reference: Fernández, F.; Fernández, A. G.; Balo, R.; Sánchez-Pedregal, V. M.; Royo, M.; Soengas, R. G.; Estévez, R. J.; Estévez, J. C. Polyhydroxylated Cyclopentane $\beta$-Amino Acids Derived from D-Mannose and D-Galactose: Synthesis and Protocol for Incorporation into Peptides. chemRxiv 2021, DOI: 10.33774/ chemrxiv-2021-kk47l-v3.

(46) Ichiyanagi, T.; Sakamoto, N.; Ochi, K.; Yamasaki, R. A Chemical Synthesis of 3-Deoxy-D- Manno -2-Octulosonic Acid from D-Mannose. J. Carbohydr. Chem. 2009, 28, 53-63.

(47) Shiozaki, M.; Tashiro, T.; Koshino, H.; Shigeura, T.; Watarai, H.; Taniguchi, M.; Mori, K. Synthesis and Biological Activity of Hydroxylated Analogues of KRN7000 ( $\alpha$-Galactosylceramide). Carbohydr. Res. 2013, 370, 46-66.

(48) Fernández, F.; Estévez, A. M.; Estévez, J. C.; Estévez, R. J. Stereocontrolled Transformation of Nitrohexofuranoses into Cyclopentylamines via 2-Oxabicyclo[2.2.1]Heptanes. IV: Synthesis of Enantiopure Methyl (1S,2R,3R,4R,5S)-5-Benzyloxycarbonylamino2,3-Isopropylidenedioxy-4-Methoxycyclopentanecarboxylate. Tetrahedron: Asymmetry 2009, 20, 892-896.

(49) Lehtilä, R. L.; Lehtilä, J. O.; Roslund, M. U.; Leino, R. Selectively Protected Galactose Derivatives for the Synthesis of Branched Oligosaccharides. Tetrahedron 2004, 60, 3653-3661.

(50) Gerlach, H. 2-(Trimethylsilyl)äthylester als Carboxylschutzgruppe; Anwendung bei der Synthese des (-)-(S)-Curvularins. Helv. Chim. Acta 1977, 60, 3039-3044.

(51) Wright, K.; Wakselman, M.; Mazaleyrat, J.-P.; Franco, L.; Toffoletti, A.; Formaggio, F.; Toniolo, C. Synthesis and Conformational Characterisation of Hexameric $\beta$-Peptide Foldamers by Using Double POAC Spin Labelling and cw-EPR. Chem. - Eur. J. 2010, 16, 11160-11166. 